\title{
Volume Changes Observed in Small Concrete Cylinders During Freezing and Thawing Using a Mercury Displacement Dilatometer
}

\begin{abstract}
By Rudolph C. Valor, Jr.
A mercury-displacement dilatometer is described for continuously determining the changes in bulk volume of small concrete cylinders during freezing and thawing. Various types of freezing and thawing cycles were employed in which the $40^{\circ}$ to $-20^{\circ} \mathrm{F}$ range was covered at various rates. The results presented are representative volume-temperature relationships obtained for specimens tested in air-dry, partially saturated, and "vacuumsaturated" moisture conditions. Relationships for air-dry specimens yielded uniform thermal-expansion data, but those for partially saturated specimens showed departures from uniformity that are ascribed to the freezing and thawing of water in the pore structures of the specimens. Vacuum-saturated specimens showed much larger departures and failed as a result of a single cycle of freezing and thawing.
\end{abstract}

\section{Introduction}

Moist, porous building materials subjected to repeated alternate cycles of freezing and thawing usually show a progressive deterioration manifested by a softening, scaling, spalling, cracking, or loss of strength or elasticity. This deterioration has generally been ascribed to a repeated straining or distending of the material that may occur as a consequence of the conversion of water to ice within the pore system of the material.

The fact that water increases in volume as it freezes (approximately $9 \%$ at $32^{\circ} \mathrm{F}$ ) has led various investigators to employ a dilatometric or displacement method for studying the volumefreezing-point relationships for a number of materials. The method has been employed by Anderson and Edlefson [1] ${ }^{1}$ and others [2] in studies of soils, by Thomas [3] in England in a comprehensive study of the frost resistance of building stone, and by Powers and Brownyard [4] in a study of saturated, hardened portland cement pastes.

The present work is part of an investigation of the physical reactions occurring in concrete specimens of different degrees of moisture saturation

\footnotetext{
Figures in brackets indicate the literature references at the end of this paper.
}

during freezing and thawing. It was believed that the measurement of transient and residual changes in bulk volume (i. e., volume of solids plus volume of pores) occurring in specimens during, and as a result of, freezing and thawing cycles of various types might provide some desired information. To attain this end, the first objective was the development of a satisfactory dilatometer.

\section{Scope}

The initial problem in the development of a satisfactory dilatometer involved the choice of a suitable displacement medium. Liquids in the hydrocarbon group, such as toluene and kerosine, had been widely used as displacement media in previous dilatometer work and were found to be satisfactory where the detection of freezing points and measurement of volume changes in fully saturated samples were required. Thomas [3], however, using ligroine (petroleum ether), found the dilatometer unreliable for measuring changes in bulk volume in partially saturated specimens of building stone during freezing and thawing. It appeared that the physical properties of petroleum ether were such that the liquid readily entered, to an undetermined extent, those pore spaces not 
filled with water. Thomas made his most satisfactory determinations by an optical-lever linear extensometer method.

For the present work, mercury was chosen as the displacement medium, because of several advantages it appeared to show over liquids in the hydrocarbon group within the desired working temperature range, $40^{\circ}$ to $-20^{\circ} \mathrm{F}$. These advantages included (1) a uniform and relatively low coefficient of thermal expansion, (2) a relatively high coefficient of thermal conductivity, (3) a low specific heat, and (4) the nonwetting property. The high density of mercury allowed a high degree of precision in the various operations preparatory to and following the dilatometer tests, since very small volumes of mercury could be accurately determined by weighing.

Mercury, however, was found to penetrate to a slight but undesirable extent the surfaces of dry or partially saturated concrete specimens. It was found necessary to treat the specimens in such a way as to render the surfaces impermeable to mercury while not interfering with the free passage of air, water, and water vapor during drying and other curing operations. This was accomplished by rubbing a cement-fine-sand mortar into the surface of each specimen, effectively "sealing" the larger pore openings and surface voids. The weight of each specimen was increased by less than 0.5 percent by this treatment.

Of the many variables in specimen condition thought to affect the reaction to freezing and thawing, the moisture condition was chosen for greatest emphasis. Specimens were air-dried and "vacuum-saturated" before the testing to provide two extremes in moisture condition; and various curing procedures were employed to provide specimens in the more normal condition of partial saturation. The specimens did not have access to additional moisture during testing in the dilatometers, since they were completely immersed in mercury. Thus the "buildup" in saturation described by Kreuger [5] and observed by Tucker, Walker, and Swenson [6] did not occur and could not be studied.

The specimens were small cylinders cast from concrete of one-mix design (plain and modified by the addition of an air-entraining agent) made with one brand of normal portland cement and one type of aggregate.
Comparison of results obtained in laboratories using a wide variety of techniques in performing freezing and thawing testing of concrete indicated the rate of temperature change as a most significant variable. For this reason variations were made in rates of cooling and heating during the freezing and thawing cycles, and also in the length of periods at constant temperature during and between cycles. Volume-temperature relationships for the various types of cycles were obtained within a single temperature range, $40^{\circ}$ to $-20^{\circ} \mathrm{F}$, which was sufficiently broad to permit the use of rather effective extremes in the rates of temperature change.

Most of the specimens tested were subjected to freezing and thawing cycles of several kinds. This was done in order that a comparison of the effects of various test procedures could be made upon a single specimen unobscured by the unpredictable dissimilarities that often occur in "duplicate" specimens.

In addition to the volume-temperature relationships, supplementary determinations were made for each specimen. The degree of saturation of a specimen was expressed as a percentage of "vacuum-saturation," based upon the weight of the specimen when oven dried, inasmuch as other means for evaluating the moisture condition were found to be less reliable. The effects of the various freezing and thawing treatments were evaluated in terms of changes in Young's modulus of elasticity (dynamic, flexural). The specimen could not conveniently be removed from the dilatometer during the progress of a cycle, or between cycles, so that normally only the total effect of a number of cycles was ascertained. This was done by obtaining the difference in Young's modulus, determined before and after the dilatometer tests.

Because of the exploratory nature of the work, the results obtained are not amenable to statistical treatment. Results presented are confined largely to figures portraying the volume-temperature behavior for approximately one-fourth of the more than 50 specimens tested. Nevertheless, certain patterns of behavior have been observed and are discussed. Such conclusions as may be implied in the discussion of results, however, apply only to the specimens tested in which the effects of brand of portland cement and type of aggregate were not included among the variables studied. 


\section{Dilatometers and Equipment}

\section{Construction of the Dilatometers}

A drawing of the dilatometer is shown in figure 1. The vertical cylindrical chamber was constructed from 0.15-in.-thick seamless mild-steel tubing 2.05 in. in internal diameter and 7.25 in. in height. The top and bottom were formed from 1-in. steel plate. The bottom plate was machined to fit the tubing and then welded into place, as shown in the drawing. The steel cover was machined to fit the top of the cylinder, and the inner surface of the cover was funnel-shaped to facilitate the removal of air entrapped in the dilatometer during the liquid filling process. The apex of the inverted funnel opened into a $5 / 8$-in.-outside-diameter threaded steel tube, to the top end of which a glass burette assembly was attached. The cover was attached to the cylinder by means of four
$1 / 4$-in. bolts, which extended through the bottom plate, and was secured by wing nuts. A compressible organic plastic gasket 0.002 -in. thick was placed between the top of the cylinder and the cover to prevent the loss of mercury.

\section{Burettes}

Measuring pipettes were used as dilatometer burettes. The pipette tips were broken off and the straight-bore stems were cemented into short lengths of threaded steel tubing to form interchangeable, detachable burette assemblies. A thin, hard-rubber gasket separated the tubing at the bottom end of the burette from the tubing that formed a part of the dilatometer cover, as shown in figure 1. One-, two-, and five-ml-capacity pipettes were used. For most tests, the 1-ml size was satisfactory, but for tests of vacuum-saturated specimens it was necessary to use the $5-\mathrm{ml}$ size.

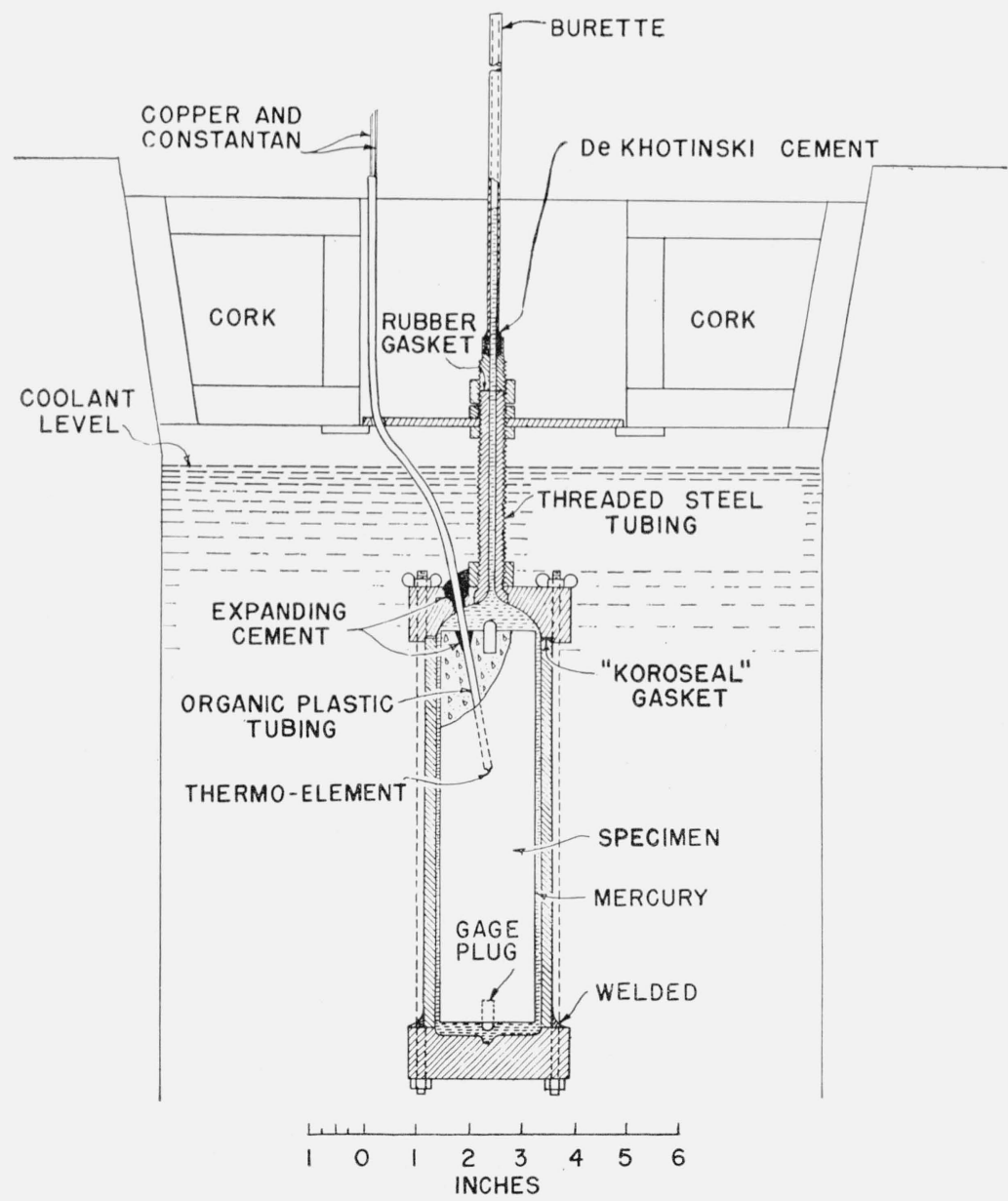

FIGURE 1. Vertical section of mercury-displacement dilatometer containing a cylindrical concrete test specimen. 
The pipettes were calibrated by the Metrology Division of the National Bureau of Standards. Only those pipettes for which the mean error of marking was less than 1 percent were used. Readings were estimated to $0.001 \mathrm{ml}$ for the 1 and $2-\mathrm{ml}$ pipettes. Therefore, changes in volume as small as 0.0003 percent could be discerned for specimens with bulk volumes ranging between 335 and $340 \mathrm{ml}$.

\section{Calibration of the Dilatometer Assemblies}

The dilatometer calibration consisted in obtaining a value for the thermal coefficient of volume change for the dilatometer chamber. This value was calculated as the volume change per degree per milliliter capacity. The capacity was the volume at $40^{\circ} \mathrm{F}$ when the dilatometer was filled to the chosen burette level. The use of a solid steel cylinder having dimensions similar to those of the concrete specimens to be described in a following section facilitated the determination.

The calibration was performed in several steps. First, the thermal coefficient of linear expansion for the steel calibration "specimen" was computed from thermal extensions and contractions, as observed by means of a Tuckerman optical-lever extensometer and autocollimator [7]. ${ }^{2}$ The specimen was placed in a controlled temperature, thermally insulated air chamber, and gage readings were observed when the system attained tem-

${ }^{2}$ A complete description of the apparatus is given in The thermal expansion of clay building bricks, by C. W. Ross [8]. perature equilibrium. The gages used were 6 in. long and were calibrated relative to a standard steel bar for which the thermal coefficient of linear expansion had been determined by the Metrology Division. The gage readings represented changes in length of the test objects relative to changes in length of the gages. The test chamber was taken through two complete cycles of temperature change so that four determinations were made. The mean value obtained for the thermal coefficient of linear expansion for the steel specimen was $6.3 \times 10^{-6}$ per degree Fahrenheit, as shown in table 1 . This value was multiplied by 3 to obtain the coefficient of cubical expansion.

TABLE 1. Thermal coefficient of linear expansion of steel calibration specimen, determined by means of Tuckerman optical lever extensometer

\begin{tabular}{|c|c|c|}
\hline \multicolumn{2}{|c|}{ Temperature } & \multirow{2}{*}{$\begin{array}{l}\text { Thermal coefficient of } \\
\text { linear expansion per } \\
\text { degree Fahrenheit }\end{array}$} \\
\hline Initial & Final & \\
\hline${ }^{\circ} F$ & $\circ F$ & \\
\hline 66.9 & 22.6 & $6.33 \times 10^{-6}$ \\
\hline 22.6 & 70.2 & 6.25 \\
\hline 70.2 & 30.2 & 6.25 \\
\hline \multirow[t]{2}{*}{30.2} & 68.0 & 6.28 \\
\hline & & Mean_..... $6.3 \times 10^{-6}$ \\
\hline
\end{tabular}

The second step in the calibration consisted in determining the burette reading change per degree Fahrenheit when the dilatometer contained the steel specimen and mercury. To obtain these data, the loaded dilatometer was immersed suc-

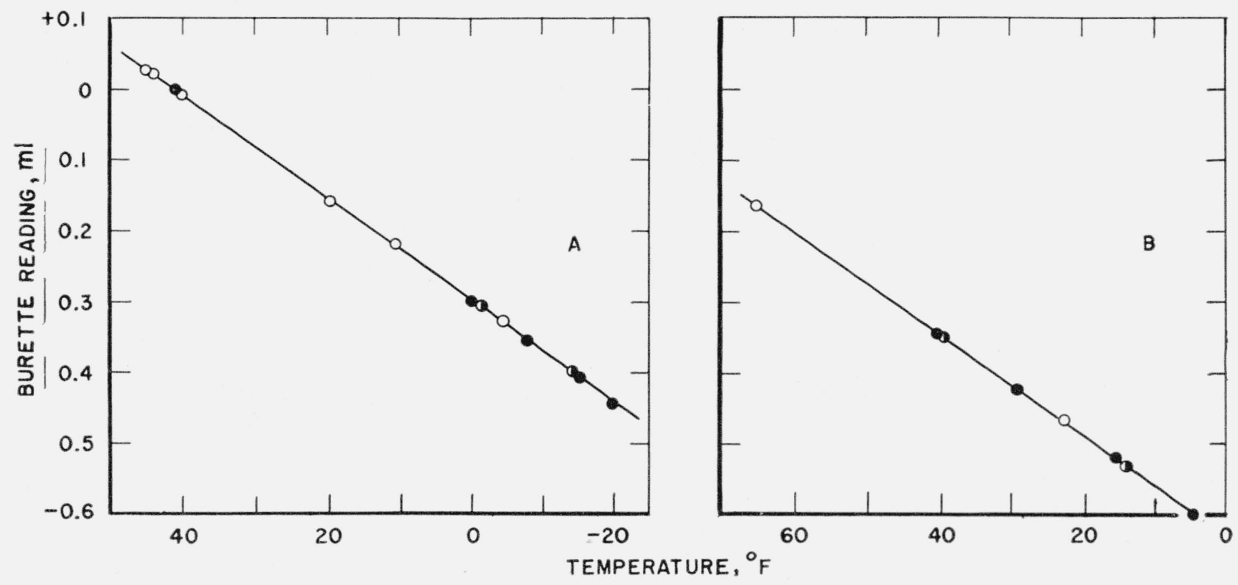

FIGURE 2. Changes in burette reading with temperature for dilatometer 1 containing a steel calibration specimen surrounded by mercury.

Two burette sizes were used A, 2-ml burette; B, 1-ml burette; $\boldsymbol{\theta}$, cooling; $\bigcirc$, heating. 
cessively in a number of constant-temperature baths between $40^{\circ}$ and $-20^{\circ} \mathrm{F}$ and held at each temperature until equilibrium was reached. Figure 2, A, shows the burette readings plotted against temperature for one of the dilatometers with a 2 -ml burette attachment. In figure 2, B, similar data are shown for the same dilatometer with a 1-ml burette and for a somewhat different temperature range. Values for the slopes were computed by the method of least squares and represent the burette reading changes per degree Fahrenheit. The total volume change per degree for the dilatometer chamber was simply the burette reading change per degree subtracted from the computed volume change per degree for the steel specimen and the mercury. The value used for the thermal coefficient of cubical expansion of mercury, $100.7 \times 10^{-6}$ per degree Fahrenheit was derived from data on the specific volume over the range $+40^{\circ}$ to $-20^{\circ} \mathrm{F}$ [9].

The following is a sample calculation for the thermal coefficient of volume change per degree Fahrenheit per milliliter capacity of dilatometer 1 with 2 -ml burette attachment:

Volume of steel specimen at $40^{\circ} \mathrm{F} \ldots \ldots . .341 .0 \mathrm{ml}$

Volume of mercury in dilatometer at

$40^{\circ} \mathrm{F}_{\ldots} \ldots . \ldots 8 \mathrm{ml}$

Capacity of dilatometer chamber at $40^{\circ} \mathrm{F}_{-} 428.9 \mathrm{ml}$

Volume change of steel specimen per degree Fahrenheit equals $341.0 \times 6.3 \times$ $10^{-6} \times 3 \ldots$

Volume change of mercury per degree Fahrenheit equals $87.9 \times 100.7 \times 10^{-6}-\ldots$

Total volume change, steel specimen and mercury, per degree Fahrenheit.......

Burette reading change per degree Fahrenheit _............................

Volume change of dilatometer chamber, per degree Fahrenheit

$0.0064 \mathrm{ml}$

$0089 \mathrm{ml}$

$0153 \mathrm{ml}$

$0072 \mathrm{ml}$

$0081 \mathrm{ml}$

Volume change of dilatometer chamber per degree Fahrenheit per milliliter capacity

Thermal coefficient of linear expansion for steel dilatometer chamber (computed as one-third of volume change per degree Fahrenheit per milliliter capacity) .....

6. $3 \times 10^{-6}$
TABLE 2. Thermal coefficients of cubical and linear expansion for dilatometer chamber 1 .

\begin{tabular}{|c|c|c|c|}
\hline \multirow{2}{*}{$\begin{array}{l}\text { Burette } \\
\text { capacity }\end{array}$} & \multirow{2}{*}{$\begin{array}{l}\text { Slope of line } \\
\text { of regression }{ }^{1} \\
\text { (milliliters } \\
\text { per degree } \\
\text { Fahrenheit) }\end{array}$} & \multicolumn{2}{|c|}{$\begin{array}{l}\text { Thermal coefficient of } \\
\text { expansion per degree } \\
\text { Fahrenheit }\end{array}$} \\
\hline & & Cubical ${ }^{2}$ & Linear ${ }^{3}$ \\
\hline \multicolumn{4}{|l|}{$m l$} \\
\hline 2. & -0.00716 & $19.0 \times 10^{-6}$ & $6.3 \times 10^{-6}$ \\
\hline $2 \ldots$ & -.00724 & 18.6 & 6.2 \\
\hline \multirow[t]{2}{*}{$1 \ldots$} & -.00713 & 18.8 & 6.3 \\
\hline & Mean... & $18.8 \times 10^{-6}$ & $6.3 \times 10^{-6}$ \\
\hline
\end{tabular}

1 Computed by the method of least squares; 2 of the 3 determinations are shown in figure 2 .

${ }^{2}$ Volume change of dilatometer chamber per milliliter of capacity per degree Fahrenheit.

${ }^{3}$ Computed as one-third of cubical coefficient.

meter [7], previously mentioned. These results are shown in table 3 . The mean value for the thermal coefficient of linear expansion, $6.45 \times 10^{-6}$ per degree Fahrenheit, obtained by the extensometer method was less than 3 percent higher than the mean value, $6.3 \times 10^{-6}$ per degree Fahrenheit, obtained by the volumetric method. The value accepted for the thermal coefficient of volume change for the entire dilatometer chamber was the one calculated from the volumetric determinations, as it was obtained under conditions most nearly simulating the method actually used for testing the concrete specimens.

TABLE 3. Thermal coefficient of linear expansion for the cylindrical portion of dilatometer (No. 1), as determined by means of the Tuckerman optical-lever extensometer

19. $0 \times 10^{-6} \mathrm{ml}$

\begin{tabular}{|c|c|c|}
\hline \multicolumn{2}{|c|}{ Temperature } & $\begin{array}{c}\text { Thermal coefficient of } \\
\text { linear expansion per } \\
\text { degree Fahrenheit }\end{array}$ \\
\cline { 1 - 1 } Initial & Final & \\
\hline${ }^{\circ} F$ & $\circ F$ & $6.45 \times 10^{-6}$ \\
66.9 & 22.6 & 6.45 \\
22.6 & 70.2 & 6.46 \\
70.2 & 30.2 & 6.44 \\
30.2 & 68.0 & \\
& & Mean ... $6.45 \times 10^{-6}$ \\
\hline
\end{tabular}

The results of the determination of the coefficients of cubical and linear expansion for the chamber of dilatometer 1 are shown in table 2 .

To provide an approximate but independent check on the calibration of the dilatometer, the thermal coefficient of linear expansion for the cylindrical portion alone of dilatometer 1 was determined by means of the optical lever extenso-
The thermal coefficient of volume change for a second dilatometer was also determined by the methods outlined above. The calibration gave a mean value identical with that obtained for the first dilatometer. The volume change of a concrete specimen tested in a dilatometer was equal to the burette reading change, plus the volume 
change of the dilatometer chamber, minus the volume change of the mercury.

\section{Refrigerated Baths}

Concrete freezing-and-thawing test equipment, in which the coolant was an ethylene glycol-water mixture, was adapted to accommodate the dilatometers. The dilatometers were suspended from wells in the covers, so that the chamber of the dilatometer was completely immersed in the coolant. The burettes extended some 4 or 5 in. above the top of the well. Since all tests and the volumetric calibration of the dilatometers were made with the dilatometers suspended identically, burette stem corrections were obviated.

Five controlled temperature baths were available for the tests. The temperature of the baths was generally controlled to within $1 \mathrm{deg} \mathrm{F}$ of the desired temperature within the $40^{\circ}$ to $-20^{\circ} \mathrm{F}$ range. In addition, the temperature of each bath could be varied within this range in steps as small as $2 \mathrm{deg} \mathrm{F}$. In operation one bath was maintained continuously at $40^{\circ} \mathrm{F} \pm 1^{\circ} \mathrm{F}$ and another near $-20^{\circ} \mathrm{F}$. In a third bath the temperature could be lowered stepwise from $40^{\circ}$ to $-20^{\circ} \mathrm{F}$ in a minimum time of about $8 \mathrm{hrs}$, and the temperature could be increased in this range at a comparable rate. More rapid cooling or heating rates were obtained by transferring dilatometers to the appropriate bath.

\section{Temperature Measurements}

All temperature measurements were made by using calibrated copper-constantan thermocouples. For the purposes of this study, equilibrium conditions were assumed to exist when the temperature difference between the center of the specimen and the bath was $0.5 \operatorname{deg} \mathrm{F}$ or less.

\section{Preparation of Test Specimens}

\section{Materials}

A portland cement was used that complied with the requirements of Federal Specification SS-C191b [10]. The chemical analysis and calculated compound composition of this cement are shown in table 4 .

Siliceous sand and $3 / 8$-in. gravel of Potomac River origin were used as aggregate. The percentage absorption by weight was 1.0 for the sand and 1.3 for the gravel. The sieve analyses for these materials, made with United States Standard Sieves, are listed in table 5.

TABLE 4. Chemical analysis and calculated compound composition of the portland cement

\begin{tabular}{|c|c|c|c|}
\hline Component & $\begin{array}{l}\text { Percent- } \\
\text { age }\end{array}$ & Component & $\begin{array}{l}\text { Percent- } \\
\text { age }\end{array}$ \\
\hline $\mathrm{SiO}_{2-}$ & 22.0 & Ignition loss & 0.8 \\
\hline $\mathrm{Fe}_{2} \mathrm{O}_{3} \ldots$ & 2.5 & Insoluble residue ...... & .1 \\
\hline $\mathrm{Al}_{2} \mathrm{O}_{3} \ldots$ & 5. 7 & $\mathrm{CHCl}_{3}$ solubility . ..... & .004 \\
\hline $\mathrm{CaO} \ldots .$. & 64.7 & & \\
\hline $\mathrm{MgO}$ & 1.6 & $3 \mathrm{CaO} \cdot \mathrm{Al}_{2} \mathrm{O}_{3} \ldots$ & 11 \\
\hline $\mathrm{SO}_{3} \ldots \ldots$ & 1. 7 & $2 \mathrm{CaO} . \mathrm{SiO}_{2} \ldots \ldots$ & 26 \\
\hline $\mathrm{K}_{2} \mathrm{O} \ldots \ldots$ & .72 & $3 \mathrm{CaO} \cdot \mathrm{SiO}_{2} \ldots \ldots$ & 49 \\
\hline $\mathrm{Na}_{2} \mathrm{O} \ldots \ldots$ & .18 & & \\
\hline
\end{tabular}

TABLE 5. Sieve analyses of aggregates

\begin{tabular}{|c|c|c|c|c|}
\hline \multicolumn{3}{|c|}{ Sand } & \multicolumn{2}{|c|}{ Gravel } \\
\hline Sieve & $\begin{array}{c}\text { Percentage } \\
\text { retained }\end{array}$ & $\begin{array}{l}\text { Cumu- } \\
\text { lative } \\
\text { percent- } \\
\text { age } \\
\text { retained }\end{array}$ & Sieve & $\begin{array}{l}\text { Percentage } \\
\text { retained }\end{array}$ \\
\hline No. $8 \ldots \ldots \ldots$ & 15.8 & 15.8 & $3 / 8$ inch ... & 4.5 \\
\hline No. $16 \ldots \ldots$ & 17.8 & 33.6 & No. $4 \ldots$ & 95.5 \\
\hline No. $30 \ldots \ldots \ldots$ & 31.0 & 64.6 & (n) & ....... \\
\hline No. $50 \ldots \ldots \ldots$ & 23.1 & 87.7 & ... . . & - n... \\
\hline No. $100 \ldots$ & 9.8 & 97.5 & (n. & -..... \\
\hline Pan & 2.5 & - n... & (n) & ....... \\
\hline Total . & 100.0 & a 299.2 & Total _.... & 100.0 \\
\hline
\end{tabular}

a This value gives a fineness modulus of 2.99 .

\section{Fabrication of the Test Specimens}

Specimens were cast from a concrete mix designed to a cement factor of six bags per cubic yard of concrete. Half of the specimens were prepared from a plain mix and half from a mix modified by the addition of an air-entraining agent. A slight adjustment in the proportion of sand was required in the modified mix to maintain the cement factor constant. The basic mix proportions were, by weight, 1 cement : 2.8 sand: 2.5 gravel, on the basis of a saturated, surface-dry condition for the aggregates. Actually, dry aggregates were used and corrections for water absorption were made in determining batch weights. The quantity of mixing water was adjusted for each batch to give a consistency on the flow table within the range of 100 to 115 percent, as determined in accordance with Federal Specification SS-C-158b [11]. A water-cement weight ratio of 0.56 produced the desired flow in the plain mixes, 
whereas 0.53 was sufficient for the aerated batches, that contained 0.01 percent by weight of cement of a proprietary resin added in neutralized solution.

The total weight of each batch of materials was approximately $2,800 \mathrm{~g}$ and was sufficient for casting three specimens. Batches were hand-mixed for $3 \mathrm{~min}$, allowed to stand for $2 \mathrm{~min}$, and remixed for a 2 -min period.

Air in the plastic mixes was determined gravimetrically by the method described in Federal Specification SS-C-158b, [11]. The plain mixes contained $2.5 \pm 0.5$ percent of air, by volume, which is a relatively large amount for a nonaerated mix, and the aerated mixes contained $5.3 \pm 0.6$ percent of air. The plain mix appeared coarse and harsh in contrast to the plasticity and cohesiveness of the aerated mix, as judged by the relative ease of mixing.

Immediately following the mixing, the test specimens $(1.92 \pm 0.01 \mathrm{in}$. in diameter and 7.20 \pm 0.10 in. in height) were molded. The cylin-, drical molds were filled vertically in three layers, and each layer was rodded with a bullet-nosed $1 / 4$-in. diameter metal rod. The bottom and top ends of the molds were closed with wooden plugs; gage points were held in place in holes in the centers of the plugs. (The gage points were available for use in determining residual length changes; only in the case of the vacuum saturated specimens were these data significant). The bottom plug also held a $1 / 8$-in. diameter metal rod, one end of

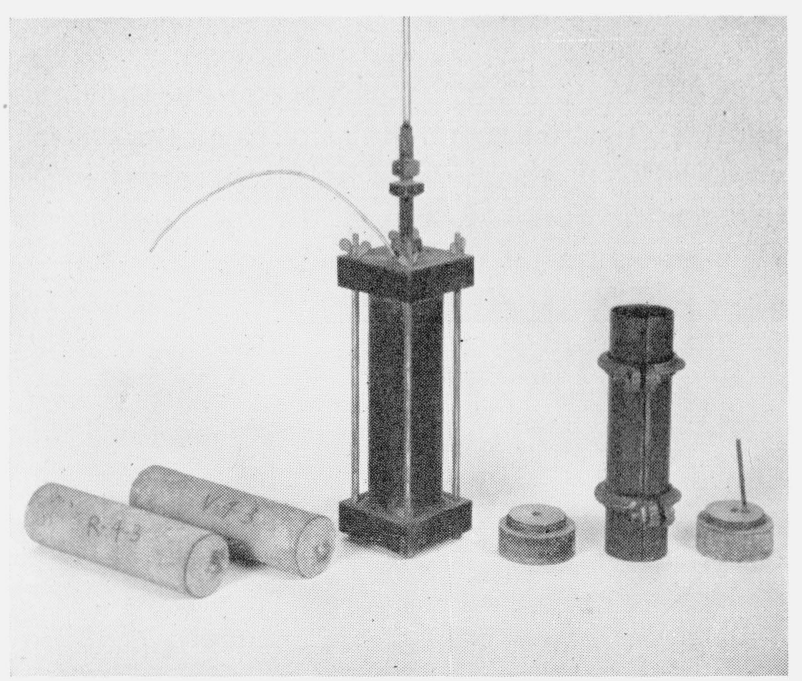

Figure 3. Typical concrete test specimens, mercury-displacement dilatometer, and specimen mold with top and bottom plugs. which extended $2 \frac{1}{2}$ in. into the specimen to a point at the center of the circular cross section. A cellophane tape sleeve was fitted on the metal rod so that when the specimen was removed from the mold the rod could be easily extracted, leaving a hole for the insertion of the thermoelement (figs. 1 and 3 ). The top plus was fitted into the mold after most of the bleeding had occurred. The specimens remained in the molds for $24 \mathrm{hr}$ before removal.

\section{Surface Treatment of the Specimens}

Preliminary experiments indicated the necessity for surface treatment of the specimen to prevent the penetration of mercury during the testing. A $1: 1$ cement-sand mortar of putty-like consistency was rubbed into the surface of each specimen upon its removal from the mold, in such a way as to fill all surface voids and larger pores. The mortar was made with the same cement used for the specimen and with sand passing a No. 50 sieve.

All specimens were subsequently stored in a fog room, maintained at $70^{\circ} \pm 2^{\circ} \mathrm{F}$ and between 95 and 100-percent relative humidity, until they were 28 days old, after which the curing procedures varied.

\section{Procedures}

\section{Preparation for the Dilatometer Tests}

The copper-constantan thermoelement and lead wires were sealed into the $1 / 8$-in.-outside-diameter organic plastic tubing so that the element barely protruded from one end of the tubing. The element and end of the tubing were coated with an organic plastic cement; after the cement had dried, the unit was inserted into the hole provided in the specimen so that the coated thermoelement was in contact with the concrete. The unit was sealed in place by tamping "iron" cement paste of dry consistency between the flared opening at the top of the specimen and the plastic tubing (fig. 1). The cement was of a quick-setting, expanding type and constricted the tubing when set.

The specimen was placed in the dilatometer after being quickly wiped with a dry cloth when necessary, and the cover was then bolted securely to the dilatometer chamber. The dilatometer was next filled with sufficient mercury to cover the specimen.

It was found that the entrapping of air upon the 
inner walls of the dilatometer and upon the surface of the specimen could be largely avoided by introducing the mercury into the dilatometer in small drops. Therefore, the mercury was poured into the dilatometer through a fine capillary that formed the stem of a glass funnel. The time required for filling was about $15 \mathrm{~min}$. The specimen did not appear to lose an appreciable amount of moisture during this period, as judged by the weight of the specimen before and after testing.

It was next necessary to seal the tubing containing the thermoelement leads at the point where it passed through the dilatometer cover. The iron cement paste was tamped between the tubing and the flared hole in the dilatometer cover. After the iron cement had set, it was coated with the organic plastic cement to protect it from the coolant liquid of the refrigerated baths.

To complete the dilatometer-specimen assembly, the burette was attached to the dilatometer and sufficient mercury was added so that the meniscus was visible in the burette. Even with careful filling it was necessary in some cases to agitate the dilatometer occasionally over a $24-\mathrm{hr}$ period, in order to remove all of the entrapped air. A simple test for determining the approximate volume of entrapped air remaining in the dilatometer consisted in applying a small amount of pressure through the open end of the burette. The amount of entrapped air was indicated by the displacement of the mercury meniscus. When this air had been removed, the mercury meniscus was adjusted to the zero reference level at $40^{\circ} \mathrm{F}$. Testing was not begun until the burette reading remained unchanged over a 24-hr period.

\section{Determination of the Degree of Saturation}

After considerable preliminary investigation, it was decided that the moisture condition of a specimen could be described best in terms of the amount of water in the specimen evaporable at $230^{\circ} \mathrm{F}$, relative to the amount of water that the specimen could contain when saturated in vacuum. This evaluation of moisture condition is termed "percentage of vacuum saturation" and was determined in the following way:

Immediately following the dilatometer tests each specimen was removed from the dilatometer and weighed. It was then heated in an oven at $230^{\circ} \mathrm{F}$ for a period of $24 \mathrm{hr}$, and weighed again. The specimen was next placed in a container and covered with a bell jar, which was then evacuated at about $4 \mathrm{~mm}$ of mercury for a period of $24 \mathrm{hr}$. At the end of this time, and while the specimen was still under vacuum, a sufficient amount of freshly distilled water was drawn into the container under the bell jar to cover the specimen. Twenty-four hours later the vacuum was released. After the specimen had remained immersed for an additional 6 days, it was removed from the container, wiped, and weighed. The percentage of vacuum saturation was then equal to:

$$
\frac{W_{i}-W_{o}}{W_{S}-W_{o}} \times 100
$$

where $W_{i}$ is the initial weight, $W_{o}$ is the oven-dry weight, and $W_{S}$ is the vacuum saturation weight. These weights were determined to the nearest $0.01 \mathrm{~g}$.

The percentage of vacuum saturation as herein defined is not presumed to represent an absolute value for the degree of saturation, inasmuch as the oven-dry basis for these determinations is subject to question. The alternative, however, of drying in a constant temperature, constant humidity room required an inconveniently long period of time. Nevertheless, a limited number of specimens was dried at $70^{\circ} \pm 2^{\circ} \mathrm{F}$ and $50 \pm 5$-percent relative humidity for a period of 6 weeks or longer. The calculated percentage of vacuum saturation on the air-dry basis was about 5 percent lower than on the oven-dry basis, in the range 65 to 80 percent of vacuum saturation. The values given in this report for the percentage of vacuum saturation represent, for each specimen, the upper limit for the true percentage of saturation. Obviously the percentage of vacuum saturation is the true percentage of saturation only if the vacuum-saturation procedure completely fills all pores with water.

\section{Methods of curing}

The various specimen moisture conditions were brought about and maintained by several curing procedures. Following the initial fog-room curing common to all specimens to the age of 28 days, the storage was as follows:

1. Specimens to be tested in an air-dry condition were stored at $70^{\circ} \pm 2^{\circ} \mathrm{F}$ and $50 \pm 5$-percent relative humidity for periods of from 60 to 120 days prior to testing. 
2. Specimens to be tested in the vacuum-saturated condition were stored at $70^{\circ} \pm 2^{\circ} \mathrm{F}$ and 50 \pm 5 -percent relative humidity for periods up to 250 days and then vacuum saturated, as described in the preceding section of this paper. The specimens were then maintained wholly immersed for as long as $1 \mathrm{yr}$ before testing them.

3. Specimens to be tested in a partially saturated condition were subjected to either of two types of curing treatment:

(a) Continuous immersion in water at $70^{\circ}$ $\pm 2^{\circ} \mathrm{F}$ until the time of test, for periods of from 1 to 12 weeks.

(b) Storage in air at $70^{\circ} \pm 2^{\circ} \mathrm{F}$ and $50 \pm 5$ percent relative humidity for at least 45 days, followed by immersion at $70^{\circ} \pm 2^{\circ} \mathrm{F}$ for periods of from 1 week to 1 year.

The values for the percentage of vacuum saturation calculated for the partially saturated specimens ranged from 75 to 85 percent for the plain specimens and from 65 to 75 percent for the aerated specimens.

\section{Types of Freezing and Thawing Treatments}

Freezing and thawing cycles of several types were obtained, within the $40^{\circ}$ to $-20^{\circ} \mathrm{F}$ range, in the following ways:

1. Slow cycle (32 hr or longer). The temperature of the bath in which the dilatometer-specimen assembly was immersed was lowered stepwise from $40^{\circ}$ to $-20^{\circ} \mathrm{F}$ in approximately $8 \mathrm{hr}$, held constant at $-20^{\circ} \mathrm{F}$ for $16 \mathrm{hr}$ or longer, and raised stepwise to $40^{\circ} \mathrm{F}$ in approximately $8 \mathrm{hr}$.

2. Fast cycles. In the $1-\mathrm{hr}$ fast cycle the dilatometer-specimen assembly, initially at $40^{\circ}$ $\mathrm{F}$, was transferred to and allowed to remain in the $-20^{\circ} \mathrm{F}$ bath for a period of $30 \mathrm{~min}$. It was then retransferred to the $40^{\circ} \mathrm{F}$ bath, where it remained for an additional $30-\mathrm{min}$ period. Figure 4 shows that $30 \mathrm{~min}$ was sufficient time for a partially saturated specimen to attain temperature equilibrium with the bath.

The interrupted fast cycle was similar to the 1-hr fast cycle, except that the dilatometer-specimen assembly remained in the $-20^{\circ} \mathrm{F}$ bath for $16 \mathrm{hr}$ or longer, between the 30-min cooling and heating periods.

3. Combined cycles. These cycles were obtained by combining a fast cooling with a slow heating, or a slow cooling with a fast heating.

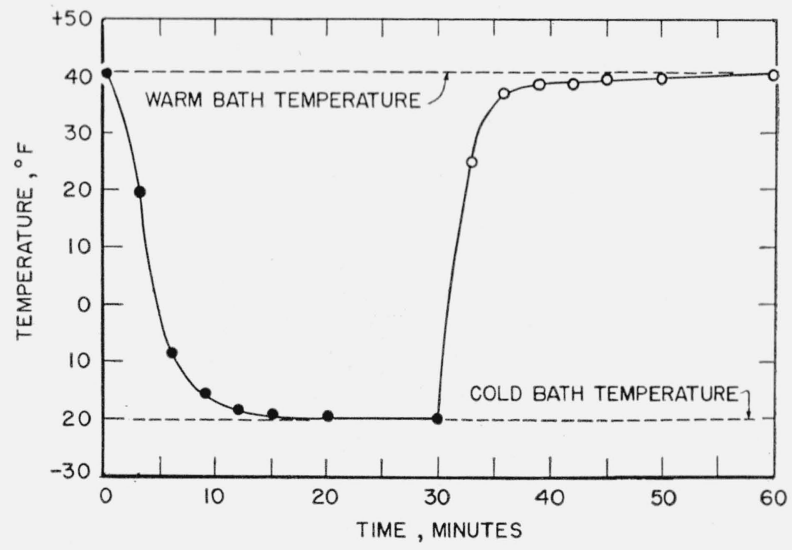

Figure 4. Time-temperature relationship for a complete 1-hour fast cycle.

Temperature is that indicated at center of cross section of a partially saturated specimen. $\bullet$, cooling; $\bigcirc$, heating.

Another type of combination treatment was employed in which a portion of the temperature range was traversed at one rate of cooling or heating and the remaining portion at a different rate.

Other types of treatment employed, but which will not be discussed in the present report, consisted of moderate cycles in which the cooling or heating was done in two or more equal temperature steps by the successive transfer of the dilatometers into a series of baths at appropriate temperatures. These cycles were used in the exploratory phases of the study that resulted in the selection of the slow cycle for special emphasis. The reasons for this emphasis will appear in the discussion in which the effects of various types of treatment are compared.

Some of the partially saturated specimens tested were subjected to all of the types of treatment described above, and others received a number of cycles of one type of treatment only.

\section{Results and Discussion}

\section{Air-Dry Specimens}

Volume-temperature relationships obtained in dilatometer tests of a plain and an aerated air-dry specimen are shown in figure 5, for successive slow and fast cycles. The moisture condition of these air-dry specimens was determined to be approximately 15 percent of vacuum saturation. The relationships are uniformly linear and not significantly different in slope for the fast and slow 
cooling or heating. In tests of other air-dry specimens, similar results were obtained.

The values for thermal coefficients of expansion obtained by this method for four air-dry specimens, are shown in table 6 . The present dilatometric method provided the conditions stated by Meyers [12] as necessary for valid determinations of the thermal coefficients of expansion of portland cement pastes, mortars, and concretes. These conditions require that "the specimens must be either in an atmosphere of controlled humidity or enclosed in airtight containers that do not restrict the movements of the specimens."

\section{Partially Saturated Specimens}

About three-quarters of the more than 50 specimens tested were in a partially saturated condition. The data for four of these specimens, which were subjected to various types of freezing and thawing cycles, are presented in figures 6 to 9 . Each graph gives the volume-temperature relationship obtained for a single cycle. ${ }^{3}$

Partial or complete results for four additional partially saturated specimens are presented in figures 10,12 , and 14 , in which only one type of

\footnotetext{
3 The sequence of cycles is designated by circled numerals. Cycles not discussed are omitted.
}

cycle is presented in each figure. Figures 11, 13, and 15 illustrate similarities, differences, or trends in the volume-temperature behavior of specimens subjected to similar treatments; these data are taken from their contexts in figures 6 to 9 .

\section{(a) General}

The data plotted in figures 6 through 9 show that in most cases, cooling caused the partially saturated specimens to contract, and heating caused them to expand. In contrast to the uniformity in results obtained for the air-dry specimens, these curves show discontinuities, points of inflection, and changes in slope in the volume-temperature behavior of the specimens during the progress of the various cycles.

In addition, for most of the cycles shown, the volume of a specimen was greater at the end than at the beginning of a cycle, indicating a "residual" expansion. These residual expansions are observed to be cumulative when the volume-temperature curves are examined in relation to the zero ordinate on each graph, which represents the volume of the specimen at $40^{\circ} \mathrm{F}$. at the start of the first cycle. The cumulative effect is evident in a vertical displacement of the starting points for the succeeding cycles away from the zero

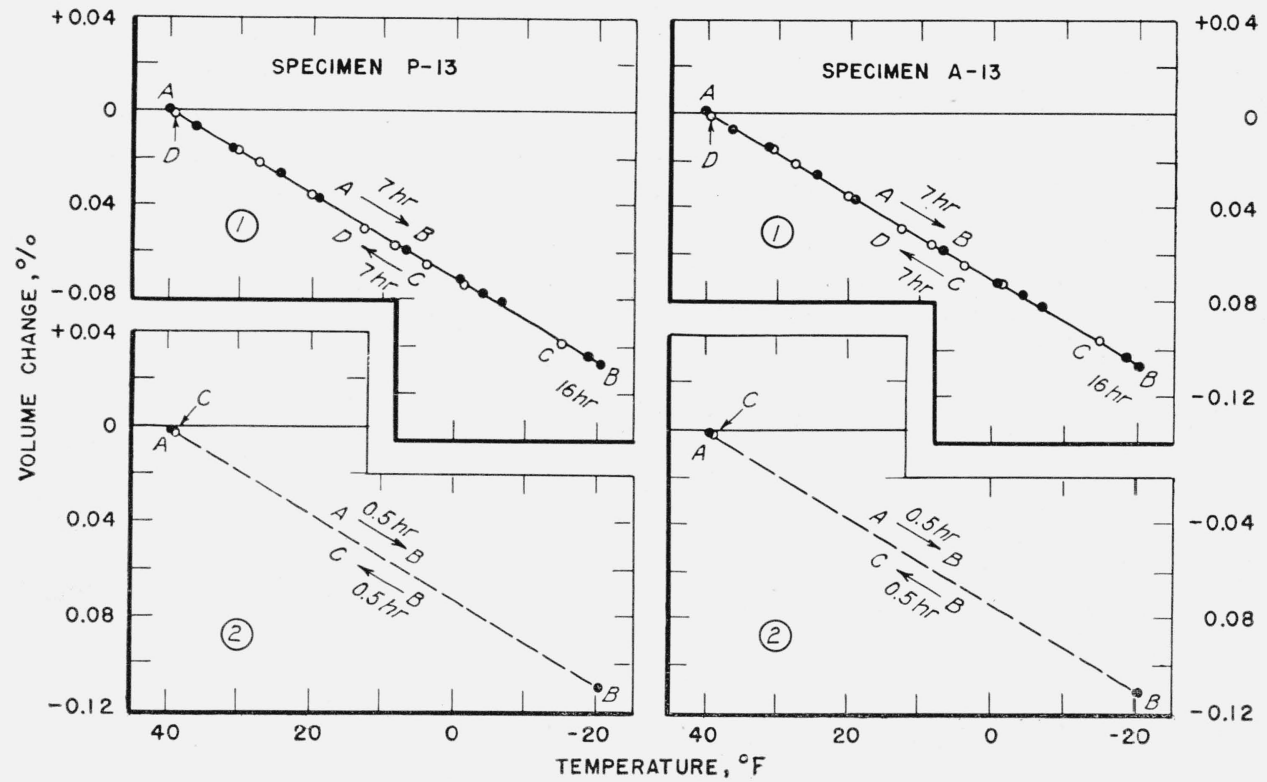

FIgURE 5. Volume-temperature relationships for a slow and a fast cycle for two air-dry specimens, P-13 (plain) and A-13 (aerated).

The thermal coefficient of linear expansion computed from these data was about $5.9 \times 19^{-6}$ per ${ }^{\circ} \mathrm{F}$ (table 6 ). Both specimens were 155 days old at the beginning of the first cycle and had been stored at $70^{\circ} \mathrm{F}$ and 50-percent relative humidity for 125 days following the initial fog-room storage. After testing, the moisture condition of these specimens was determined to be 15 percent of vacuum saturation.

, Cooling; $\bigcirc$, heating. 
TABLE 6. Thermal coefficients of cubical and linear expansion calculated from results of dilatometer tests of air-dry specimens

\begin{tabular}{|c|c|c|c|c|c|c|c|}
\hline \multirow{2}{*}{ Specimen } & \multirow{2}{*}{ Date } & \multirow{2}{*}{$\begin{array}{l}\text { Temperature } \\
\text { range }\end{array}$} & \multirow{2}{*}{$\begin{array}{l}\text { Time } \\
\text { re- } \\
\text { quired } \\
\text { to cover } \\
\text { range }\end{array}$} & \multirow{2}{*}{$\begin{array}{l}\text { Specimen } \\
\text { volume } \\
\text { change } \\
\text { per degree } \\
\text { Fahrenheit }\end{array}$} & \multirow{2}{*}{$\begin{array}{l}\text { Volume } \\
\text { of speci- } \\
\text { men }\end{array}$} & \multicolumn{2}{|c|}{$\begin{array}{c}\text { Thermal coefficient of } \\
\text { expansion per degree } \\
\text { Fahrenheit }\end{array}$} \\
\hline & & & & & & Cubical & Linear a \\
\hline \multirow{8}{*}{$P-13$ b } & $6 / 8$ & $\begin{array}{c}{ }^{\circ} F . \\
40.2 \text { to }-20.3\end{array}$ & $\begin{array}{l}\min \\
430\end{array}$ & $\begin{array}{c}m l \\
\text { c } 0.00595\end{array}$ & $\begin{array}{c}m l \\
336.4\end{array}$ & $17.7 \times 10^{-6}$ & \\
\hline & $6 / 9$ & -14.8 to 39.5 & 425 & .00602 & 500.4 & 17.9 & $\begin{array}{l}3.9 \times 10 \\
6.0\end{array}$ \\
\hline & $6 / 9$ & 39.5 to -20.3 & 30 & .00607 & ...... & 18.1 & 6.0 \\
\hline & $6 / 9$ & -20.3 to 39.0 & 30 & .00592 & -.... & 17. 6 & 5.9 \\
\hline & $7 / 12$ & 40.7 to -16.0 & 30 & . 60606 & $\ldots$ & 18.0 & 6.0 \\
\hline & $7 / 12$ & -16.0 to $\quad 40.3$ & 30 & .00610 & -.... & 18.1 & 6.0 \\
\hline & $7 / 13$ & 40.0 to -19.1 & 90 & .00598 & ...... & 17. 8 & 5.9 \\
\hline & $7 / 13$ & -19.1 to 40.0 & 30 & .00598 & $\ldots$ & 17. 8 & 5. 9 \\
\hline \multirow{8}{*}{$A-13 b$} & $6 / 8$ & 40.2 to -20.3 & 430 & c. 00593 & 335.3 & 17.7 & 5.9 \\
\hline & $6 / 9$ & -14.8 to 39.5 & 425 & .00600 & ...... & 17.9 & 6.0 \\
\hline & $6 / 9$ & 39.5 to -20.3 & 30 & .00602 & ...... & 17.9 & 6.0 \\
\hline & $6 / 9$ & -20.3 to 39.0 & 30 & .00597 & -.... & 17.8 & 5.9 \\
\hline & $7 / 12$ & 40.7 to -16.0 & 30 & .00601 & ..... & 18.0 & 6.0 \\
\hline & $7 / 12$ & -16.0 to 40.3 & 30 & .00601 & ...... & 18.0 & 6.0 \\
\hline & $7 / 13$ & 40.0 to -19.1 & 90 & .00587 & ..... & 17.5 & 5.8 \\
\hline & $7 / 13$ & -19.1 to 40.0 & 30 & .00579 & ..... & 17.3 & 5. 8 \\
\hline \multirow{4}{*}{$P-24 d$} & $11 / 12$ & 71.0 to $\quad 3.3$ & 465 & .00596 & 334.0 & 17. 9 & 6.0 \\
\hline & $11 / 13$ & 5. 3 to 52.0 & 20 & .00590 & ...... & 17. 7 & 5. 9 \\
\hline & $11 / 13$ & 52.0 to 6.7 & 30 & .00584 & ...... & 17.5 & 5.8 \\
\hline & $11 / 13$ & 6.7 to 70.2 & 410 & .00593 & ..... & 17.8 & 5. 9 \\
\hline \multirow{4}{*}{$A-24 d$} & $11 / 12$ & 71.0 to & 465 & .00601 & 336.1 & 17. 9 & 6.0 \\
\hline & $11 / 13$ & 5. 3 to 52.0 & 20 & .00595 & -.... & 17.7 & 5. 9 \\
\hline & $11 / 13$ & 52.0 to $\quad 6.7$ & 30 & .00594 & ..... & 17.7 & 5.9 \\
\hline & $11 / 13$ & 6.7 to 70.2 & 410 & .00596 & ...... & 17.7 & 5. 9 \\
\hline
\end{tabular}

a Computed as one-third of cubical coefficient.

b 155 days old at start of tests; stored at $70^{\circ} \pm 2^{\circ} \mathrm{F}$ and $50 \pm 5$ percent relative humidity for 125 days prior to test.

c First four determinations computed from data shown in figure 5.

d 640 days old at start of tests; stored in fog room at $70^{\circ} \pm 2^{\circ} \mathrm{F}$ for 80 days from time of fabrication, totally immersed for 160 days at $70^{\circ} \pm 2^{\circ} \mathrm{F}$, and then stored at $70^{\circ} \pm 2^{\circ} \mathrm{F}$ and $50 \pm 5$ percent relative humidity for 400 days.

ordinate. The total residual volume change for all specimens discussed are shown in table 7 .

(b) Description of the Volume-Temperature Relationships for the Various Types of Cycles

Slow cycle. As shown in figures 6 to 9 , tests of partially saturated specimens subjected to various types of cycles were started with a slow cycle. The general characteristics of the volume-temperature relationships for this type of cycle are shown in figure 10 for the initial slow cycle given to two partially saturated specimens. These specimens were approximately the same in degree of moisture saturation but differed widely in age and curing.

The specimens contracted uniformly during cooling at the start of the initial slow cycle to temperatures as low as $21.5^{\circ} \mathrm{F}$. This cooling and super- cooling, ${ }^{4}$ is indicated by the line $A B$ in figure 10 , $A$ and $B$. At point $B$ an abrupt increase in the temperature and volume of each specimen occurred, presumably as water within the pore structure began to freeze. Maximum values for volume and temperature (point $C$ ) were attained within a few seconds. The bath, dilatometer, and mercury surrounding the specimen remained at the temperature to which the system had been cooled when freezing occurred, or slightly lower, so that $C$ was a point of nonequilibrium. Usually within 15 min the temperature of the specimen returned to equilibrium with the bath, and during this period the volume of the specimen decreased, as indicated in figure 10 , by the location of point $D$. Cooling was resumed when point $D$ had been observed, and

\footnotetext{
4 Supercooling as herein used is defined as cooling of a specimen below the freezing point of water without thereby inducing freezing of the water within the pore structure of the specimen, as indicated by volume changes.
} 
TABLE 7. Effect of freezing and thawing cycles upon volume and elasticity of specimens for which volume-temperature relationships are presented in figures 5 to 16

\begin{tabular}{|c|c|c|c|c|c|c|c|}
\hline $\begin{array}{l}\text { Speci- } \\
\text { men a }\end{array}$ & Age & Condition & $\begin{array}{l}\text { Percentage } \\
\text { of vacuum } \\
\text { saturation }\end{array}$ & $\begin{array}{l}\text { Number } \\
\text { of cycles }\end{array}$ & $\begin{array}{c}\text { Total } \\
\text { residual } \\
\text { volume } \\
\text { change }\end{array}$ & $\begin{array}{c}\text { Change in } \\
\text { Young's } \\
\text { modulus } \\
\text { (dynamic) b }\end{array}$ & Figure in text \\
\hline $\mathrm{P}-13$ & $\begin{array}{c}\text { Days } \\
155\end{array}$ & Air-dry & 15 & & $\begin{array}{c}\text { Percent } \\
0\end{array}$ & $\begin{array}{c}\text { Percent } \\
-4\end{array}$ & 5 \\
\hline A-13 & 155 & $\ldots$. do & 15 & 5 & 0 & -4 & 5 \\
\hline $\mathrm{P}-27$ & 90 & Partially saturated & 75 & 15 & +0.100 & -27 & $6,11,13,15$ \\
\hline$A-27$ & 90 & do do & 67 & 15 & +.040 & -11 & $7,11,13,15$ \\
\hline $\mathrm{P}-23$ & 80 & _..... do & 85 & 11 & +.135 & -34 & $8,11,13,15$ \\
\hline A-19 & 95 & _.... do & 65 & 17 & +.065 & -13 & $9,11,13$ \\
\hline $\mathrm{P}-11$ & 360 & _....... do & 78 & 8 & +.085 & -37 & • 10 \\
\hline $\mathrm{P}-26$ & 37 & _.... do do... & 77 & 18 & +.085 & -19 & $\cdot 10$ \\
\hline$P-29$ & 120 & ...... do.. & 81 & 7 & +.040 & -17 & 12 \\
\hline $\mathrm{P}-30$ & 120 & .....do_ & 78 & 7 & +.060 & -13 & 14 \\
\hline $\mathrm{P}-13$ & 650 & Vacuum saturated. & 100 & 1 & +.400 & -65 & 16 \\
\hline$A-13$ & 650 & ...... do ............ & 100 & 1 & +.310 & -60 & 16 \\
\hline
\end{tabular}

\& The specimens are listed in the order in which they appear in the discussion. The plain specimens are designated by the letter $\mathrm{P}$, and the aerated specimens by the letter $\mathrm{A}$.

b Changes were computed from determinations made prior to the start and $48 \mathrm{hr}$ after the completion of the dilatometer tests, except for specimens $\mathrm{P}-13$ and A-13. For these specimens the second determination was made 1 week after the completion of the dilatometer tests.

. ${ }^{\circ}$ Figure 10 shows only the first cycle.

was continued to the $-20^{\circ} \mathrm{F}$ end point, except for necessary interruptions to obtain a sufficient number of burette and equilibrium temperature readings to establish the nature of the volume-temperature curve.

Holding the system at or near $-20^{\circ} \mathrm{F}$ overnight $(16 \mathrm{hr})$ usually produced no appreciable further change in the volume of the specimen. In many cases $-20^{\circ} \mathrm{F}$ could not be reached during the first $8 \mathrm{hr}$ of the test because of mechanical difficulties. However, it was found that the temperature gradually decreased to $-20^{\circ} \mathrm{F}$. during the night, and the volume indication obtained $24 \mathrm{hr}$ after the start of the cycle produced a continuation of the curve obtained during the first $8 \mathrm{hr}$.

Heating was begun about $24 \mathrm{hr}$ after the start of the cycle. Figure 10 shows that the specimens increased uniformly in volume as the temperature was raised, and also that the volume at any given temperature up to about $+20^{\circ} \mathrm{F}$ was somewhat greater during heating than it had been during cooling. A change in slope occurred in the heating curve above $+20^{\circ} \mathrm{F}$. A comparison of the relationships presented in figures $10, \mathrm{~A}$ and $\mathrm{B}$ (and also those shown for the initial cycles in figures 6 through 9) shows that the manner in which the slope changed varied. In the curve shown in figure $10, \mathrm{~A}$, the change in slope was sufficient to produce a sharp point of inflection, and at about $30^{\circ} \mathrm{F}$ the volume of the specimen decreased as the temperature increased. A minimum value for the volume of the specimen in this region occurred between $31^{\circ}$ and $32^{\circ} \mathrm{F}$ when all ice within the pore structure had presumably melted, following which the specimen again increased in volume as the temperature was raised to $40^{\circ} \mathrm{F}$. The relationship in figure $10, \mathrm{~B}$, showed only a gradual decrease in slope above $+20^{\circ} \mathrm{F}$. Between $32^{\circ}$ and $40^{\circ} \mathrm{F}$ the slope of the heating curve for each specimen was essentially the same as that of the initial cooling curves. In both instances the distance $A F$ is a measure of the residual expansion.

Thermal contraction and "shrinkage" during slow cooling. An obvious difference between figure $10, \mathrm{~A}$ and $\mathrm{B}$, appears in the nature of the cooling curves at temperatures below that of the discontinuity attributed to initial freezing at point $C$. In figure $10, \mathrm{~A}$, the volume-temperature relationships preceding and following the discontinuity are nearly parallel. Such relationships may be said to represent an idealized or expected behavior of moist porous materials during freezing. 


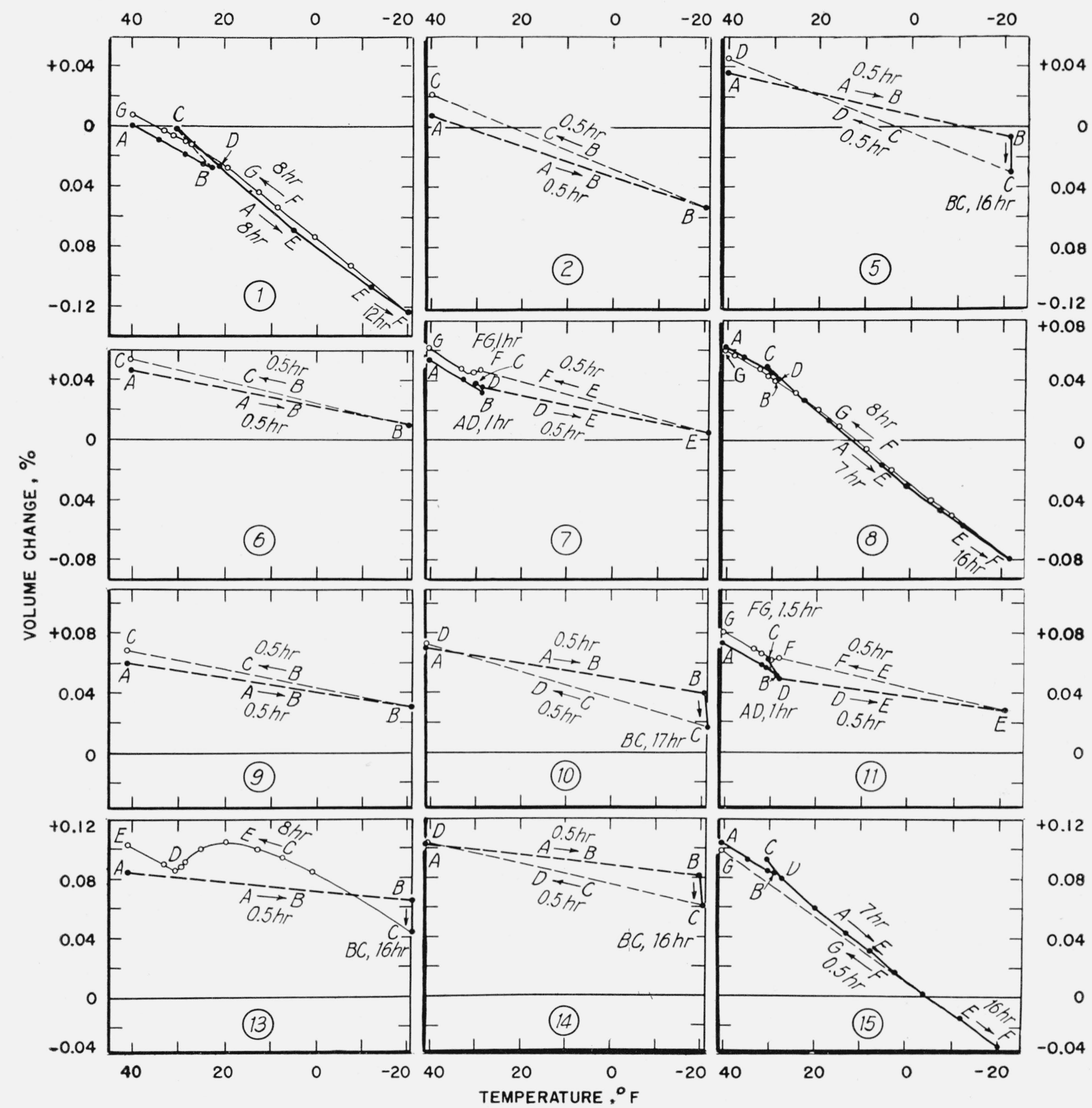

FIGURE 6. Volume-temperature relationships for 12 freezing and thawing cycles of various types as obtained for the plain partially saturated specimen $P-2 \%$.

Cycles 1 and 8 were slow cycles; 2, 5, 6, 9, 10, and 14 were 1-hour and interrupted fast cycles; 7, 11, 13, and 15 were combined cycles of several kinds; and 3,4 , and 12 , of a type not discussed, are omitted. The specimen was 90 days old at the beginning of the first cycle, and had been immersed in water at $70^{\circ} \mathrm{F}$ for 60 days following the initial fog-room storage. The moisture condition was determined to be 75 percent of vacuum saturation. This specimen decreased 27 percent in Young's modulus (dynamic, flexural) during the testing. $\bullet$, Cooling; $\bigcirc$, heating. 


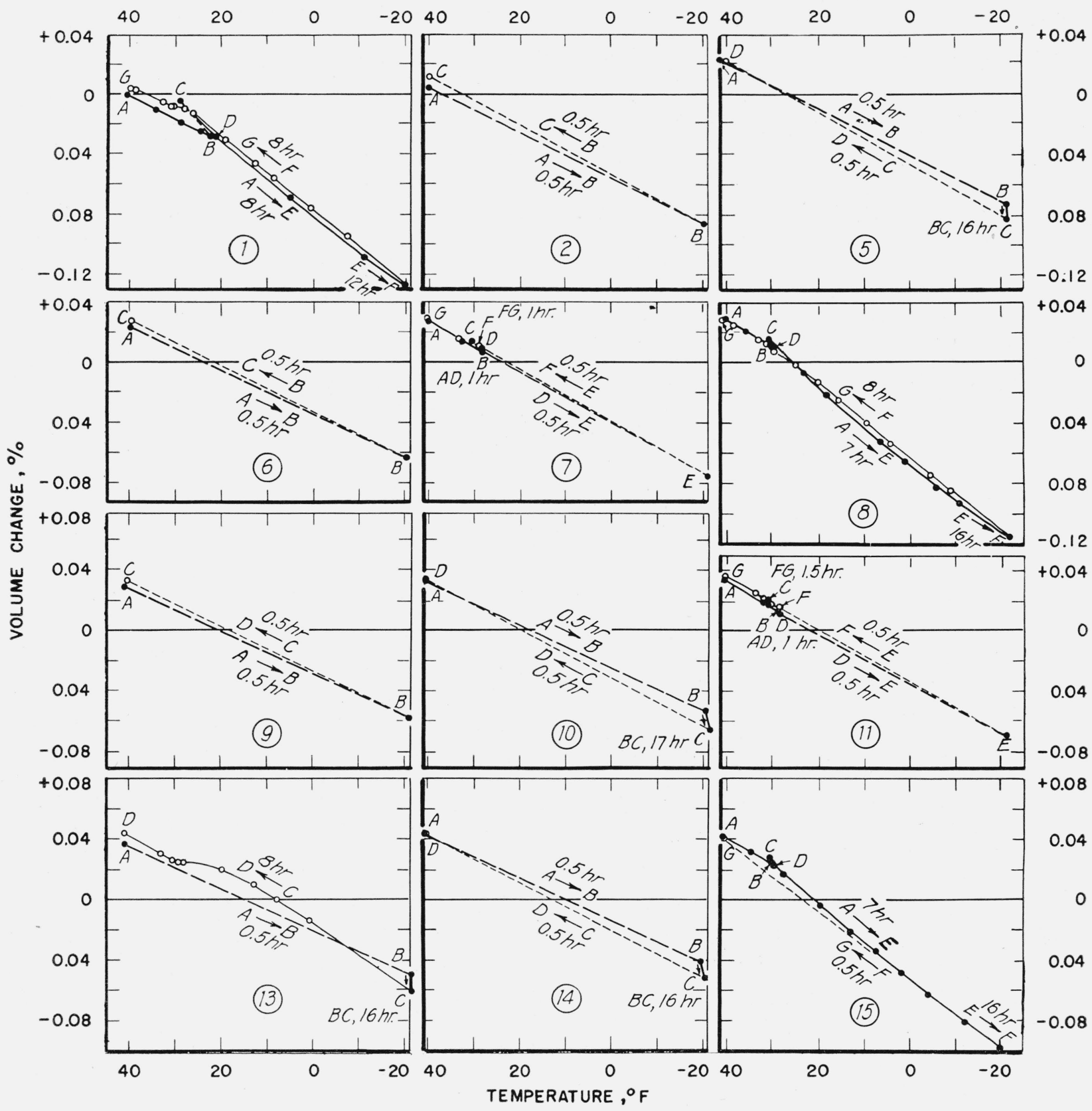

FIGURE 7. Volume-temperature relationships for 12 freezing and thawing cycles of various types as obtained for the aerated partially saturated specimen $A-2 \%$.

Cycles 1 and 8 were slow cycles; 2, 5, 6, 9, 10, and 14 were 1-hour and interrupted fast cycles; 7, 11, 13, and 15 were combined cycles of several kinds; and 3 , 4 , and 12 of a type not discussed, are omitted. The specimen was 90 days old at the beginning of the first cycle, and had been immersed in water at $70^{\circ} \mathrm{F}$ for 60 days following the initial fog-room storage. The moisture condition was determined to be 67 percent of vacuum saturation. This specimen decreased 11 percent in Young's modulus (dynamic, flexural) during the testing. Cooling; $\bigcirc$, heating. 


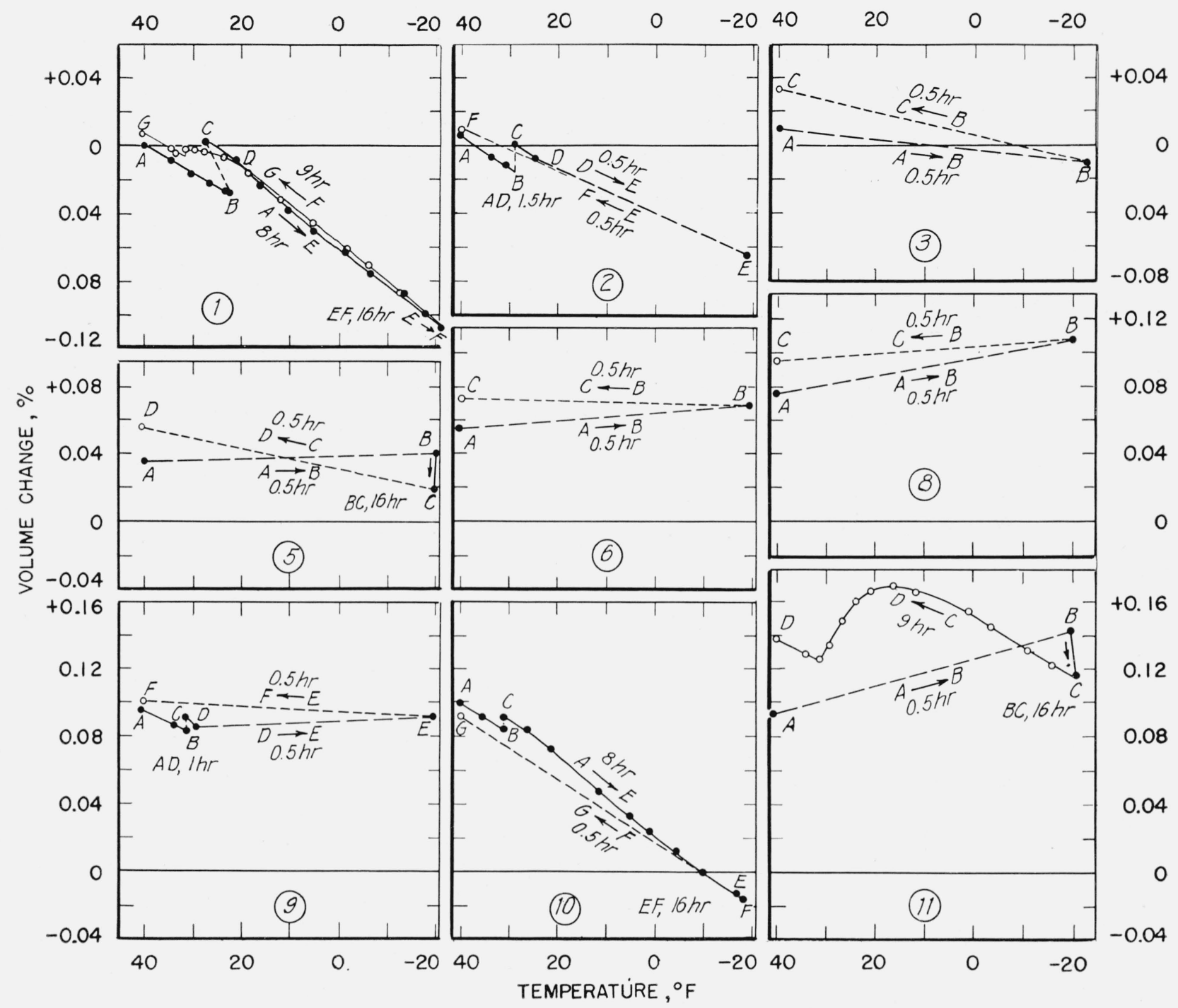

FIGURE 8. Volume-temperature relationships for nine freezing and thawing cycles of various types as obtained for the plain partially saturated specimen P-2S.

Cycle 1 was a slow cycle; $3,5,6$, and 8, were 1-hour and interrupted fast cycles; 2, 9, 10, and 11, were combined cycles of several kinds; and 4 and 7 , of a type not discussed, are omitted. The specimen was 80 days old at the beginning of the first cycle, and had been immersed in water for 49 days at $70^{\circ} \mathrm{F}$ following the initial fog-room storage. The moisture condition was determined to be 85 percent of vacuum saturation. This specimen decreased 34 percent in Young's modulus (dynamic, flexural) during the testing and was found to be one of the least resistant among the specimens tested. 


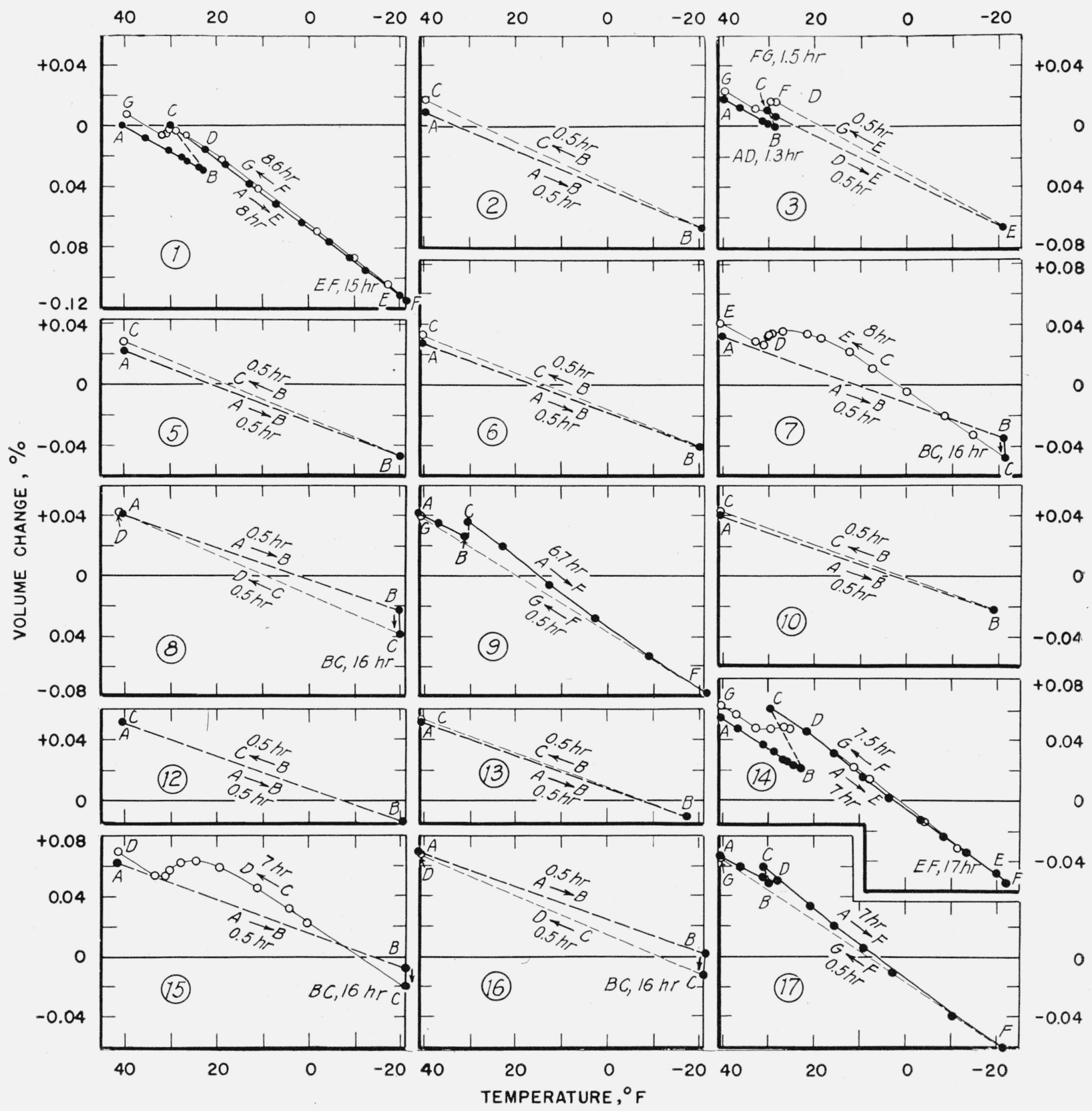

FIGURE 9. Volume-temperature relationships for 15 freezing and thawing cycles of various types as obtained for the aerated partially saturated specimen $A-19$.

Cycles 1 and 14 were slow cycles; $2,5,6,8,10,12,13$, and 16 were 1 -hour and interrupted fast cycles; $3,7,9,15$, and 17 were combined cycles of several kinds; and 4 and 11, of a type not discussed, are omitted. The specimen was 95 days old at the beginning of the first cycle. It had been stored at $70^{\circ} \mathrm{F}$ and 50-percent relative humidity for 45 days following the initial fog-room storage and had then been immersed in water at $70^{\circ} \mathrm{F}$ for 20 days before testing. The moisture condition was determined to be 65 percent of vacuum saturation. This specimen decreased 13 percent in Young's modulus (dynamic, flexural) during the testing. Cooling; $\bigcirc$, heating. 
Relationships of the type shown in figure 10 , $B$, however, were obtained for most of the partially saturated specimens. Here the volumetemperature relationships preceding and following the initial freezing were notably different in slope. In the figures the linear relationship $A B$, obtained during the initial cooling, has been extrapolated to $B^{\prime}$. It may be assumed that the line $A B^{\prime}$ represents the volume-temperature behavior of the specimen when freezing does not occur, or when a temperature range that does not include the freezing point of water is employed. Hence, the slope of line $A B^{\prime}$ represents the thermal coefficient of cubical expansion of the specimen. The relationship actually obtained, $C E$, however, intersects and descends below the extrapolated line, and the total contraction during cooling from $+40^{\circ}$ to $-20^{\circ} \mathrm{F}$ appears to be greater than it would have been had freezing not occurred. Thus, the total volume change during cooling appeared to consist not only of the normal thermal contraction, upon which the abrupt expansion caused by freezing (point $C$ ) is superimposed, but also of a "shrinkage" factor. This factor appears to occur solely as an effect of freezing, since it was absent in the results obtained for the air-dry specimens. The term shrinkage is used here to distinguish the effect from the purely thermal contraction, and not to imply that the mechanism by which it occurs is known. Thomas has [3] ascribed extra-thermal length contractions, observed during the freezing of partially saturated sandstones and other materials, to internal "drying" that resulted when water was, in effect, "removed" by its conversion to ice.

Volume-temperature relationships for repeated slow cycles.-In figure 11, the volume-temperature relationships for repetitions of the slow cooling are abstracted from their contexts in figures 6 to 9 . Also shown are the slow cooling relationships for some of the "combined" cycles. The most obvious point of variation among the relationships obtained for each specimen is in the temperature to which the specimen was cooled before the initial freezing occurred. For slow coolings following the first, it is seen that the amount of supercooling was notably reduced, i. e., freezing was apparently initiated at a higher temperature than in the first cycle. An exception is noted for the fourteenth cycle shown in figure 9 for specimen A-19 and, more clearly, in figure 11. During the fourteenth cycle for this specimen, the amount of supercooling was as much as during the first cycle. In all previous testing schedules the specimendilatometer assembly was maintained at $40^{\circ} \mathrm{F}$ between successive cycles, and the period of such storage never exceeded $72 \mathrm{hr}$. In this case, however, a period of 5 days at $40^{\circ} \mathrm{F}$ intervened be-

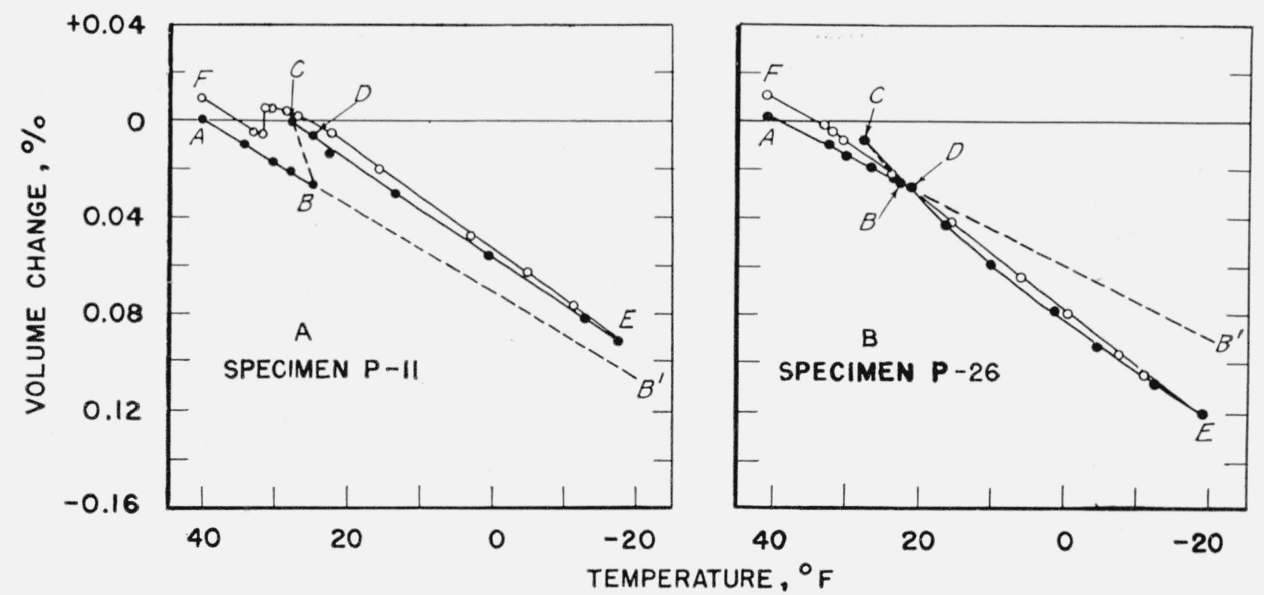

FIGURE 10. Volume-temperature relationships for a slow cycle as obtained for two plain partially saturated virgin specimens of similar degree of saturation, but of considerably different ages and curing histories.

Specimen P-11, which was 1 year old at the time of the test, had been stored at $70^{\circ} \mathrm{F}$ and 50 -percent relative humidity for 60 days following the initial fog-room storage, and had been immersed in water at $70^{\circ} \mathrm{F}$ for 270 days before testing. The moisture condition was determined to be 78 percent of vacuum saturation. Specimen P-26, which was 37 days old at the time of test, had been immersed for 7 days at $70^{\circ} \mathrm{F}$ following the initial fog-room storage. The moisture condition was determined to be 77 percent of vacuum saturation. Specimen P-11, which decreased 37 percent in Young's modulus (dynamic, flexural) during eight cycles, was regarded as one of the least resistant of all the specimens tested. Specimen P-26 decreased only 19 percent during 18 cycles of similar types.

- Cooling; $\bigcirc$, heating. 


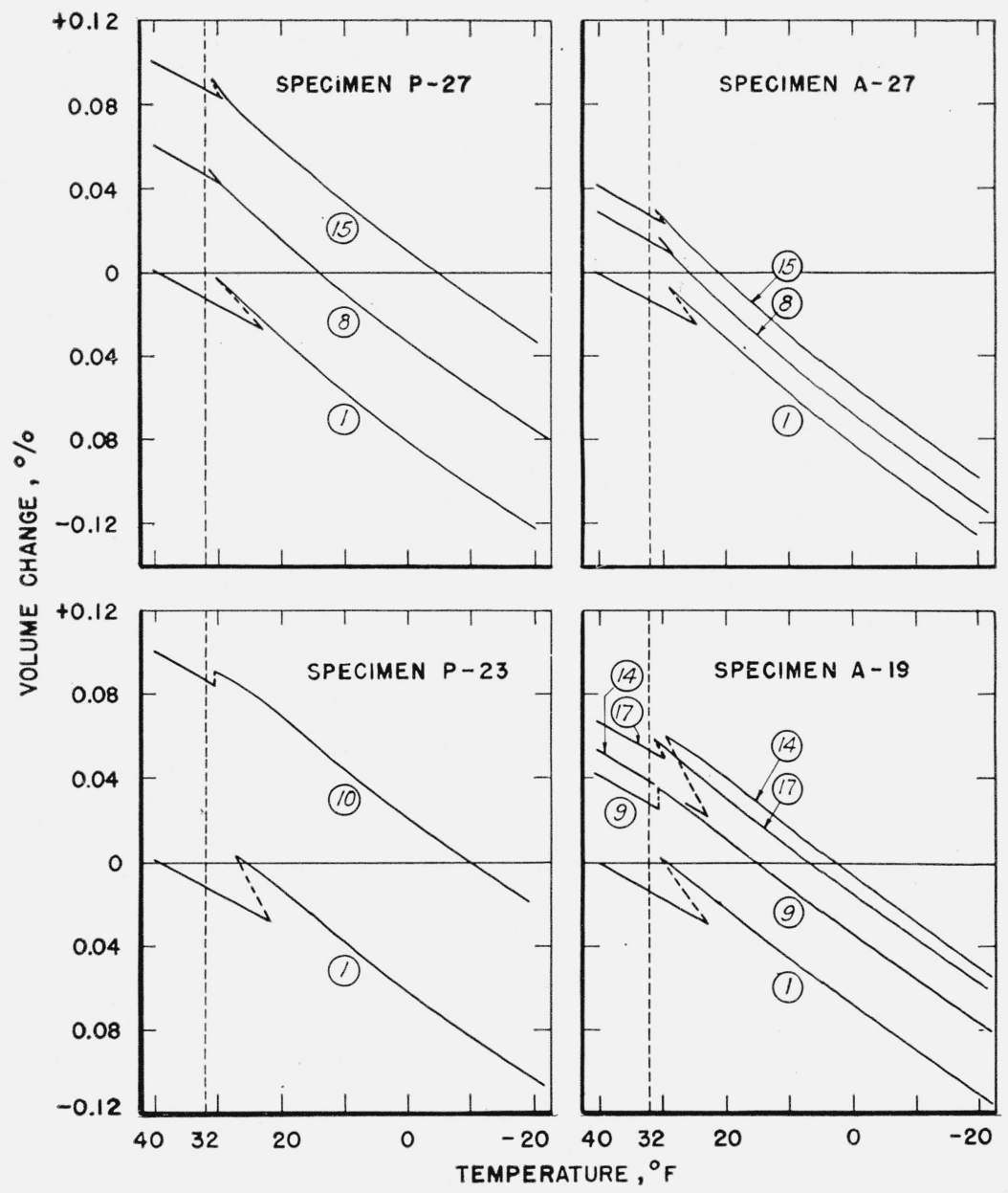

FIGURE 11. Volume-temperature relationships for four partially saturated specimens during slow cooling.

The volume-temperature relationships are removed from their contexts in figures 6 to 9 and plotted to a common origin for each specimen. The number of the cycle appears with each curve. The relative extent of super-cooling may be noted with reference to the broken line, which is the $32^{\circ}$ abscissa.

tween the thirteenth and fourteenth cycles. Otherwise, the cycle was no different from preceding slow cycles.

Volume-temperature relationships are presented in figure 12 for specimen $\mathrm{P}-29$, which was subjected to seven successive slow cycles. The periods of storage at $40^{\circ} \mathrm{F}$ between cycles, or the "recovery times," were varied. The recovery times and temperatures to which each specimen was supercooled are shown in table 8 for the partially saturated specimens discussed in this report, including specimen $\mathrm{P}-29$. About $100 \mathrm{hr}$ appeared to be a "critical" duration of recovery time for all specimens tested. When this time was less than $100 \mathrm{hr}$, supercooling of from $1^{\circ}$ to $5^{\circ} \mathrm{F}$ occurred during the next cooling; when this time exceeded $100 \mathrm{hr}$, supercooling was increased to from $7^{\circ}$ to $10.5^{\circ} \mathrm{F}$ during the next cooling. The critical duration was exceeded, among the specimens listed in table 8 , only for the specimens $\mathrm{A}-19, \mathrm{P}-11, \mathrm{P}-26$, and $\mathrm{P}-29$. Variations in the degree of supercooling, other than those appearing to occur in relation to the critical recovery time, appeared to depend upon unknown factors, but not upon how greatly the recovery time exceeded or fell short of $100 \mathrm{hr}$.

Fast cycles. During the 1-hr fast cycle only three burette readings were obtained. The first and third readings were observed at $40^{\circ} \mathrm{F}$ at the start and completion of the cycle, and the difference between them was the residual volume change. The intermediate reading was observed 
TABLE 8. Effect of "recovery time" upon supercooling during slow and slow-fast cooling in partially saturated specimens a

\begin{tabular}{|c|c|c|c|c|}
\hline $\begin{array}{l}\text { Speci- } \\
\text { men }\end{array}$ & Cycle b & Cooling & $\begin{array}{c}\text { Recovery } \\
\text { time }\end{array}$ & $\begin{array}{c}\text { Supercooled } \\
\text { to }-\end{array}$ \\
\hline \multirow{7}{*}{$F-27$} & & & $h r$ & ${ }^{\circ} \mathrm{F}$ \\
\hline & 1 & Slow $\ldots \ldots . .$. & -...... & 23.0 \\
\hline & 7 & Slow-fast_.. & 3.0 & 28.5 \\
\hline & 8 & Slow $\ldots$ & 17.0 & 29.0 \\
\hline & 11 & Slow-fast... & 0.5 & 28.5 \\
\hline & 15 & Slow $\ldots . . .$. & 70.5 & 28.5 \\
\hline & 1 & Slow $\ldots . .$. & - & 22.5 \\
\hline \multirow{4}{*}{$\mathrm{A}-27$} & 7 & Slow-fast.... & 3.0 & 28.5 \\
\hline & 8 & Slow $\ldots$ & 17.0 & 29.0 \\
\hline & 11 & Slow-fast & 0.5 & 28.5 \\
\hline & 15 & Slow & 70.5 & 29.5 \\
\hline \multirow{4}{*}{$\mathrm{P}-23$} & 1 & Slow & $\ldots$ & 22.0 \\
\hline & 2 & Slow-fast & 38.0 & 30.0 \\
\hline & 9 & ..... do & 0.5 & 30.5 \\
\hline & 11 & Slow & 7.0 & 30.5 \\
\hline \multirow{5}{*}{ A-19 } & 1 & Slow $\ldots . . .$. & ..... & 23.0 \\
\hline & 3 & Slow-fast & 3.0 & 28.5 \\
\hline & 9 & Slow & 2.0 & 30.0 \\
\hline & 14 & $\ldots$ do & 140.0 & 22.5 \\
\hline & 17 & .... do .... & 1.0 & 29.5 \\
\hline \multirow{4}{*}{$\mathrm{P}-11$} & 1 & Slow & & 24.5 \\
\hline & 5 & Slow-fast.. & 0.5 & 30.0 \\
\hline & 6 & Slow $\ldots \ldots$ & 470. 0 & 24.5 \\
\hline & 7 & ..... do & 1140.0 & 23.0 \\
\hline \multirow{6}{*}{$\mathrm{P}-26$} & 1 & Slow & ...... & 22.5 \\
\hline & 4 & Slow-fast.. & 4. 0 & 27.0 \\
\hline & 6 & Slow & 1.0 & 27.5 \\
\hline & 7 & ..... do & 45. 0 & 27.0 \\
\hline & 10 & ..... do & 460.0 & 22.5 \\
\hline & 13 & ..... do & 70.0 & 28.0 \\
\hline \multirow{7}{*}{$\mathrm{P}-29$} & 1 & Slow $\ldots$ & . & 22.0 \\
\hline & 2 & ..... do & 111.0 & 21.5 \\
\hline & 3 & ... do ... & 16.0 & 30.0 \\
\hline & 4 & .... do ... & 112.0 & 24.0 \\
\hline & 5 & ..... do ... & 17.0 & 29.0 \\
\hline & 6 & .... do .... & 16. 0 & 28.5 \\
\hline & 7 & _.... do _. & 136. 0 & 22.5 \\
\hline
\end{tabular}

a The specimens are listed in the order in which they are discussed in the text.

b The cycles omitted from this table were those in which the cooling was fast or moderate, and in which supercooling could not be detected.

at $-20^{\circ} \mathrm{F}, 30 \mathrm{~min}$ after the transfer of the dilatometer from the $40^{\circ} \mathrm{F}$ bath. The data given in figures 6 to 9 show rather significant differences in the amount of contraction during the fast cooling, not only among the various specimens, but also, for specimens $\mathrm{P}-27$ and $\mathrm{P}-23$, among the several fast cycles administered to each specimen. This is shown more clearly in figure 13 , where data for the fast coolings only are plotted. Specimens A-27 and A-19 show only a slight change in slope with repetitions of the fast cooling, whereas specimen $\mathrm{P}-27$ and particularly, specimen $\mathrm{P}-23$, show a marked change in slope.

The interrupted fast cycle differed from the 1hr fast cycle only in the prolonging of immersion of the dilatometer in the $-20^{\circ} \mathrm{F}$ bath for $16 \mathrm{hr}$ or longer before retransfer of the dilatometer to the $40^{\circ} \mathrm{F}$ bath. At least one interrupted fast cycle was given to each of the specimens for which data are shown in figures 6 to 9 . The data show that the specimens decreased in volume during the prolonged immersion at approximately $-20^{\circ}$ $\mathrm{F}$. The decrease in volume was found to continue at a gradually diminishing rate for several days for some specimens allowed to remain at $-20^{\circ} \mathrm{F}$ for that length of time.

Combined cycles. Data are presented in figure 14 for a specimen subjected to seven successive fast cooling-slow heating cycles. These data show the previously described contraction at $-20^{\circ} \mathrm{F}$ following the fast cooling, and the volume-temperature relationship for the slow heating. The heating curve for each cycle shows a change in slope beginning at a lower temperature than was indicated during the complete slow cycles shown for other specimens. This is indicated in figures 6 to 9 for specimens receiving both types of cycles. Compare heating curves for cycles 1 and 8 with that for cycle 13 in figures 6 and 7 ; note also cycle 11 , figure 8 , and cycles 7 and 15 , figure 9 .

Volume-temperature relationships for a type of combined cycle in which the combination was reversed from that described in the preceding paragraph, i. e., a slow cooling-fast heating cycle, are also shown. Note cycle 15 in figures 6 and 7 , cycle 10 in figure 8 , and cycles 9 and 17 in figure 9 . In each case there was a residual contraction at the completion of the cycle, in contrast to the residual expansions shown for most of the other types of cycles.

Also shown in figures 6 to 9 are volume-temperature relationships for cycles in which "slow-fast" cooling was employed. The initial, slow-cooling portion of the relationship includes the discontinuity attributed to freezing and is, to this point, the same as the previously described slow cooling. This may be seen; for example, in cycles 7 and 11 in figures 6 and 7 . After the specimen returned to equilibrim following the discontinuity at point $C$, it was cooled in the remaining portion of the $40^{\circ}$ to $-20^{\circ} \mathrm{F}$ range in one step, indicated by the broken lines $D E$. The similarity between this 


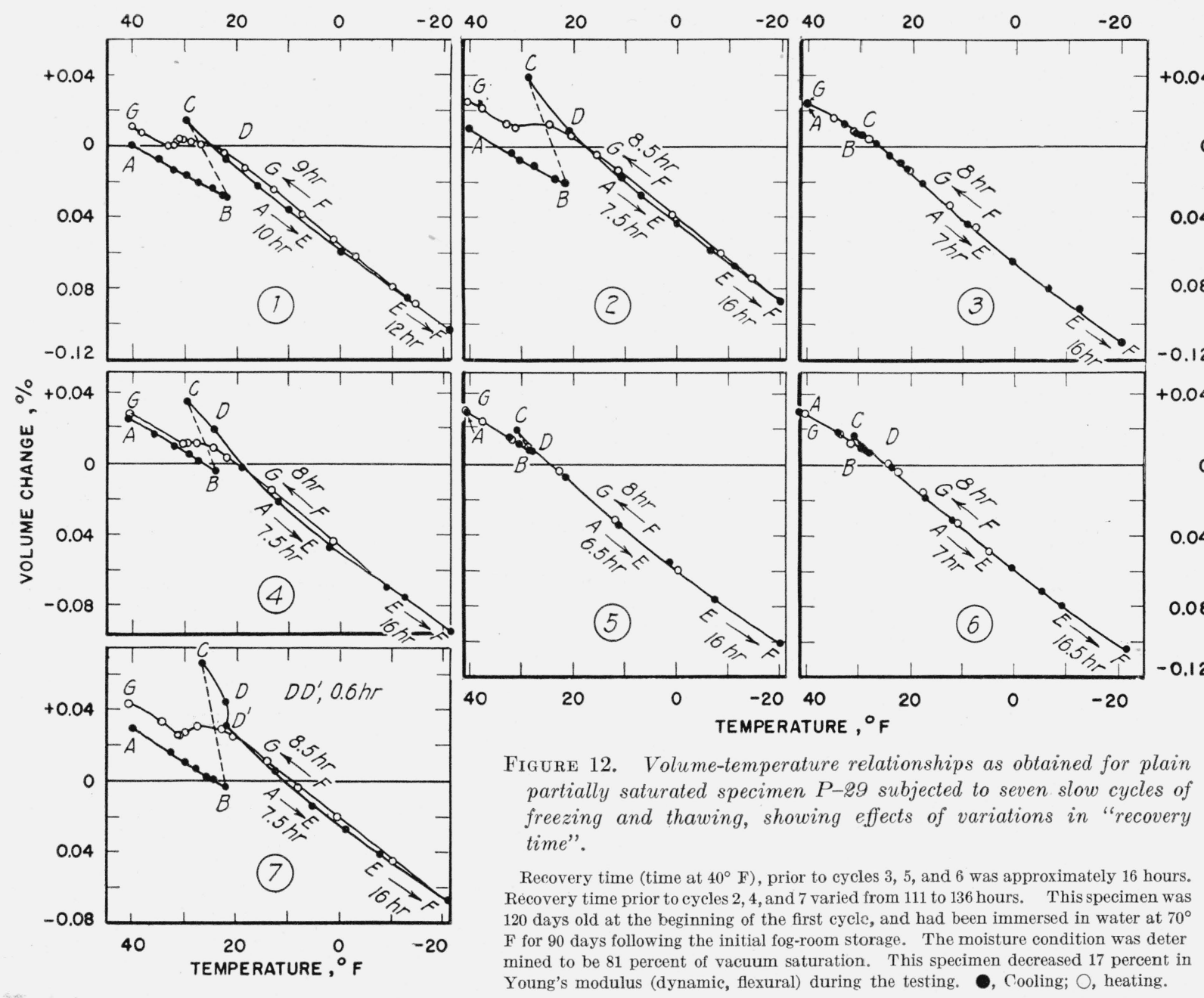

fast cooling portion of the cycle and the cooling during a fast cycle for each specimen is obvious. To interpret the relationships obtained, it appears that some of the water in the pore structures of the specimens froze at point $C$ and then additional water froze during the subsequent fast cooling. That all freezable water in a porous material does not freeze at the same temperature has been pointed out by a number of other investigators $[3,4,14]$.

Comparison of various types of freezing and thawing cycles. The data presented in figure 15 show differences in volume behavior of three specimens when subjected to a sequence of different types of cooling. These data are taken from figures 6,7 , and 8 . In figure 15 the starting point for each curve $\left(40^{\circ} \mathrm{F}\right)$ is drawn to coincide with an arbitrary " 0 " reference ordinate. The sequence of treatments as given was fast, slowfast, slow, and fast for each specimen. The slow and slow-fast coolings were accompanied by a minimum of supercooling.

The relationships exhibit a pattern common to all partially saturated specimens subjected to successive cycles of different kinds. In each case the slow cooling (maximum rate of temperature drop $10^{\circ} \mathrm{F} / \mathrm{hr}$ ) produced the largest contraction, and the fast cooling (maximum rate of temperature drop $10^{\circ} \mathrm{F} / \mathrm{min}$ at the center of a specimen) produced the smallest contraction.

Although the volume behavior during repeated slow coolings showed no systematic variation when supercooling was a minimum (fig. 11), repeated fast coolings produced progressively smaller contractions in all but a few, aerated, specimens (fig. 13). 


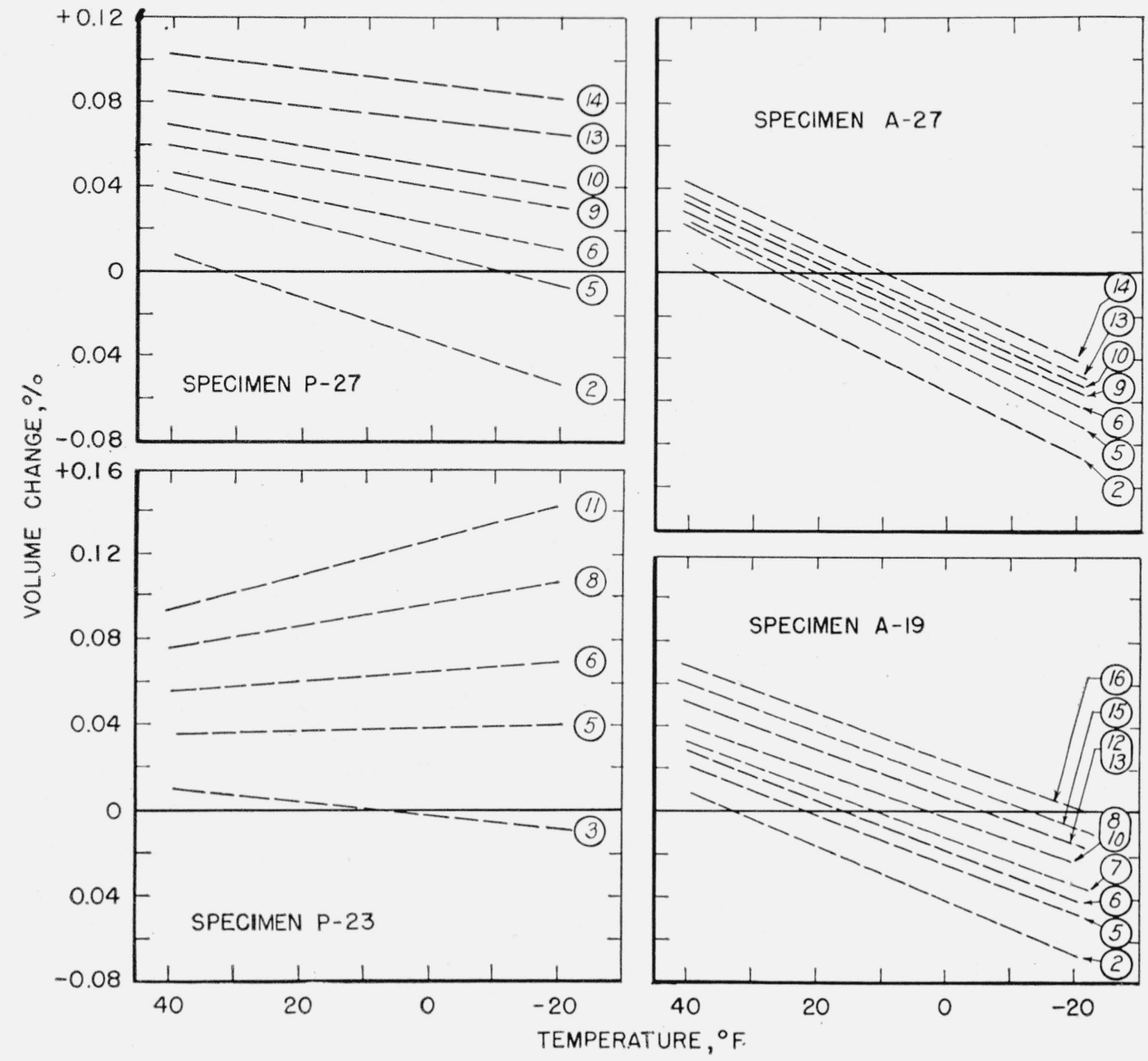

FIGURE 13. Volume-temperature relationships for four partially saturated specimens during repeated fast coolings.

The volume-temperature relationships are removed from their contexts in figures 6 to 9 and plotted to a common origin for each specimen. The number of the cycle is designated by a numeral. Specimens P-27 and A-27, which were identical in age and curing history, were tested simultaneously in two dilatometers and followed identical testing schedules.

That the gradual change in the condition of each specimen, reflected by the decrease in contraction with repeated fast coolings, did not distort the pattern shown is indicated in figure 15 . The sequence of treatments started and ended with identical fast coolings. In each case the differences in contraction for these two fast coolings were small in comparison with the indicated differences between successive treatments of different kinds. An examination of table 7 shows that the specimens for which data are shown in figure 15 are representative of the range in degree of saturation, and resistance to freezing and thawing as indicated by the decrease in dynamic Young's modulus.

There are indications in figures 6 to 9 and 12 that, at least between $0^{\circ}$ and $-20^{\circ} \mathrm{F}$, the volume of each specimen at a given temperature during a slow cooling was an irreducible minimum. The final temperature decrement, $E F$, occurring in most cases over a period of approximately $16 \mathrm{hr}$, produced a continuation of the volume-temperature relationship without a significant change in slope. In contrast the specimens were shown to contract at constant temperature $\left(-20^{\circ} \mathrm{F}\right)$ following a fast cooling. This contraction may have been similar to the shrinkage effect (discussed on page 17) observed in some of the partially saturated specimens during a slow cooling. That the shrinkage during slow cooling was not simply a decrease in strain, is indicated by the magnitude of the effect, which greatly exceeded the maximum strain discerned in the discontinuity following supercooling. It was not possible, however, to distinguish between shrinkage and a decrease in strain in the fast cycle, 


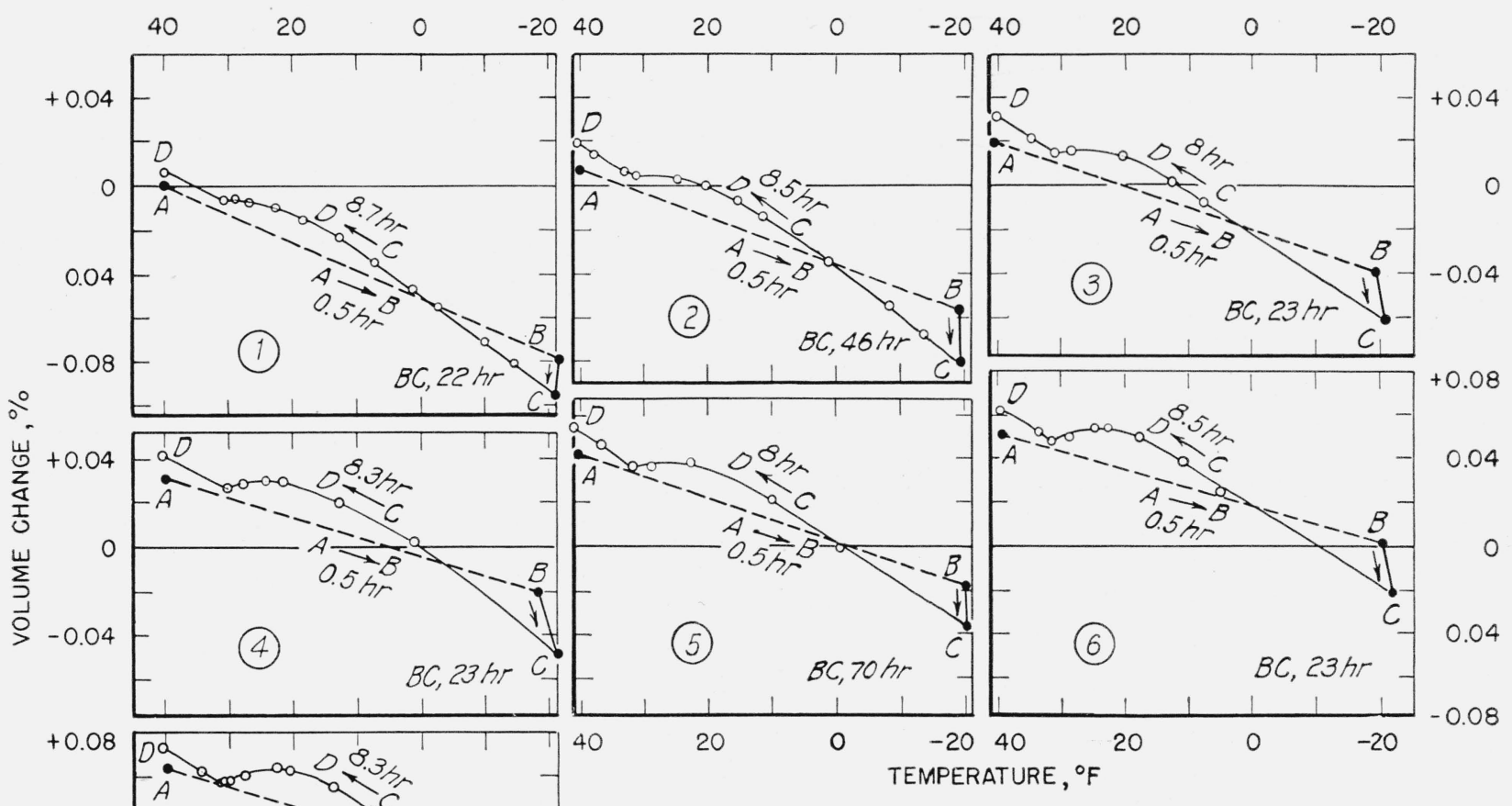

Figure 14. Volume-temperature relationships as obtained for a partially saturated specimen $P-30$ subjected to seven combined fast cooling-slow heating cycles of freezing and thawing.

This specimen, cast from the same batch as specimen P-29 (fig. 12), was 120 days old at the beginning of the first cycle, and had been immersed in water at $70^{\circ} \mathrm{F}$ for 90 days following the initial fog-room curing. The moisture condition was determined to be 78 percent of vacuum saturation. This specimen decreased 13 percent in Young's modulus (dynamic, flexural) during the testing. - Cooling; $\bigcirc$, heating.
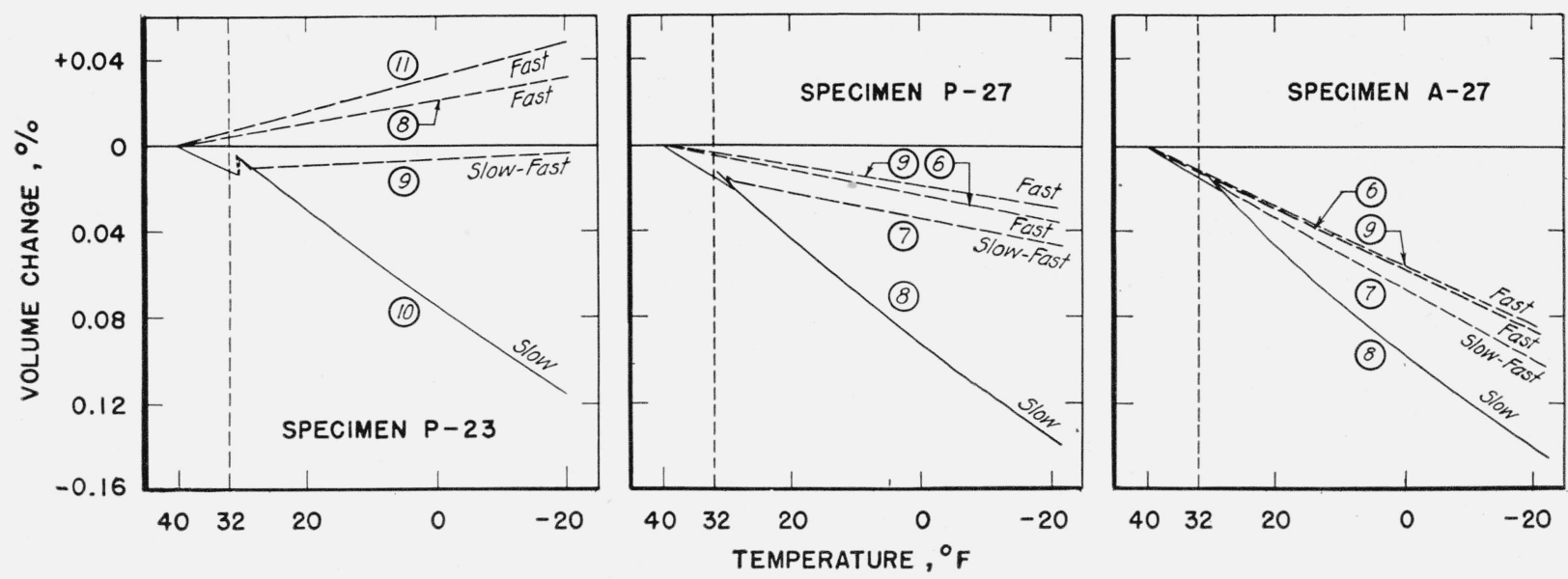

FIgURE 15. Comparison of volume-temperature relationships for three types of cooling as obtained for three partially saturated specimens during successive cycles of freezing and thawing.

The relationships are removed from their contexts in figures 6,7 , and 8 , and drawn with starting points coinciding with an arbitrary origin. In each case the cycles were administered in the order fast, slow-fast, slow, and fast. 
because observations were made only for the extremes of the $+40^{\circ}$ to $-20^{\circ} \mathrm{F}$ temperature range. A decrease in strain or relaxation phenomenon should be expected according to the hydraulic pressure hypotheses of Thomas [3], Kennedy [13], and Powers [14]. These hypotheses attribute the disruptive force of freezing in porous materials to a hydraulic pressure produced by a movement of water ahead of the "ice front" and generated by the expansion accompanying: the freezing of water rather than to pressure developed directly from the growth of ice crystals. The occurrence of stress relaxation, however, would not preclude the occurrence of the shrinkage effect during a fast cooling.

The observed differences in contraction of a given specimen when cooled in different ways were considered to be a measure of differences in strain. Considering the treatments that produced the least contraction as most severe, the various types of cooling would rank, in the order of decreasing severity, fast, slow-fast, and slow.

Although comparisons of cooling effects could be made by examining transient volume behavior, the effects of varying the rate of heating could not be similarly analyzed. The end of the heating period, which completed a cycle, usually resulted in a residual volume change, measurable at $40^{\circ} \mathrm{F}$. The residual changes (normally expansions) were usually small in comparison with the strains observed at $-20^{\circ} \mathrm{F}$, and reflected the effects of the complete cycle, i. e., the effects of cooling as well as heating. Although the effects of varying the rate of heating were not investigated as extensively as the rate of cooling, comparison of the slow and fast heating indicated that the slower treatment produced greater positive residual volume changes, other things being equal. Examples of this may be found in cycles 13 and 14, figures 6 and 7 ; the only difference between the treatments given occurs, in each case, in the rate of heating. Similar illustrations are cycles 7 and 8, and cycles 15 and 16 in figure 9.

Examination of figures 6 to 9 indicates that appreciable residual contractions resulted only from the combination of the slow cooling (minimum supercooling) and the fast heating. The need for further study, to evaluate properly the relative effects of variations in the rate of heating is recognized. However, a tentative rating of the complete cycles, arranged in the order of increasing residual expansions, is as follows:

1. Slow cooling ${ }^{5}$-fast heating.

2. Slow cooling ${ }^{5}$-slow heating.

3. Fast cooling-fast heating.

4. Fast cooling-slow heating.

Wide variations in the magnitude of residual expansions during repeated slow cycles appeared to be related to the previously discussed variations in supercooling. A slow cooling with a maximum of supercooling produced a larger residual expansion in a given specimen than a slow cooling in which supercooling was reduced to a minimum, other things being equal. In the fast cooling, however, the large initial temperature gradient probably prevented the appearance of the effects of supercooling. No general comparison, applicable to all specimens, of the effects of the fast coolings and the slow cooling with a maximum of supercooling, may be made. Among the specimens more susceptible to damage by freezing and thawing, the fast cooling produced the larger residual expansions, whereas among less susceptible specimens the reverse was often true. In many cases, a slow cycle with a maximum degree of supercooling produced about the same residual expansion as a fast cycle.

It is recognized that a "swelling" as a result of thawing, corresponding to the shrinkage effect during freezing, may have confused the observations. Such a swelling, resulting from one cycle, may have continued into a succeeding cycle. It is believed, however, that such effects were not sufficiently large to vitiate the observed pattern of volume behavior.

\section{(c) Differences Among Specimens}

Differences between plain and aerated specimens. The nondestructive dynamic determination of Young's modulus of elasticity, which is widely used in freezing and thawing studies, was used as a criterion of the relative "soundness" condition of specimens subjected to the dilatometer tests. The moduli were computed from values for the resonant frequency of flexural vibration, determined prior to, and following the dilatometer tests. A specimen showing a decrease in dynamic

\footnotetext{
${ }_{5}^{5}$ Supercooling absent or reduced to a minimum.
} 
$E$ of 25 to 30 percent was considered to have "failed."

Most of the partially saturated specimens were tested in pairs (one plain and one aerated), in which both specimens received identical treatments. The different pairs of specimens, however, did not all receive similar treatment, and therefore only a composite analysis of specimen moisture condition and of the effects of the freezing and thawing treatments may be given.

\begin{tabular}{|c|c|c|}
\hline & Plain & Aerated \\
\hline $\begin{array}{l}\text { Average percentage of vacuum } \\
\text { saturation (10 pairs of speci- } \\
\text { mens) } \\
\text { Average percentage change in } \\
\text { dynamic } E_{-} \\
\text {Average percentage total resid- } \\
\text { ual volume change }\end{array}$ & $\begin{array}{r}78 \\
-22 \\
+0.092\end{array}$ & $\begin{array}{r}69 \\
-13 \\
+0.043\end{array}$ \\
\hline
\end{tabular}

For each pair of specimens, the plain specimen was of a higher degree of saturation, decreased more in dynamic $E$, and increased more in volume than the aerated specimen.

Effect of degree of saturation and type of curing upon volume-temperature behavior. The differences in behavior between plain and aerated specimens of comparable age and curing were believed to be related to differences in degree of saturation. The values obtained for the percentage of vacuum saturation ranged from 75 to 85 percent for the plain specimens, and from 65 to 75 percent for the aerated specimens. In general, there was a difference of 10 percent of vacuum saturation between plain and aerated specimens cured and tested in pairs. The four specimens for which data are presented in figures 6 to 9 are representative of specimens in the range 65 to 85 percent of vacuum saturation.

As seen in these figures, differences in the initial slow cycle volume temperature relationships among different specimens did not appear to be related to differences in the degree of saturation. For example, there is little difference between the initial slow cycle relationships for specimens $\mathrm{P}-27$ and A-27 (figs. 6, 7, and 11) despite the 8-percent difference in the degree of saturation. In contrast, the slow-cycle relationships shown in figure 10 for specimens $\mathrm{P}-11$ and $\mathrm{P}-26$ were notably different, but the specimens were of approximately the same degree of saturation. An examination of the data shows no great differences in residual volume changes resulting from slow cycles given specimens of different degrees of saturation. Results of the type presented in figure 13 for the fast cycles, however, show rather large differences among specimens differing in percentage of vacuum saturation. These specimens were of comparable ages, but the curing of specimen A-19 included a drying period, whereas the others were continuously wet prior to testing. Specimen $\mathrm{P}-23$ not only showed the least contraction during the initial fast cooling, but also showed the greatest change in the amount of contraction during repeated fast coolings. A relatively large expansion occurred during the fast cooling for the 11th and final cycle. The volumetemperature relationships for the last two cycles, as seen in figure 8, may be of interest in that they show the transient volume changes in a specimen definitely failing. This specimen decreased 34 percent in dynamic $E$ during 11 cycles of freezing and thawing.

An insufficient amount of data was obtained to allow a study of the effect of type of curing on the transient and residual volume changes to be made. It can only be stated that type of curing and age of specimen appear to affect these changes for some of the types of cycles.

\section{Vacuum-Saturated Specimens}

Two specimens, $\mathrm{P}-13$ and $\mathrm{A}-13$, which were first tested in the air-dry condition (fig. 5), were then vacuum-saturated and immersed in water for 1 yr. The vacuum-saturation procedure described previously was used to provide specimens for test with a maximum degree of moisture saturation. Figure 16 shows the volume-temperature relationships obtained for these specimens during one slow cycle of freezing and thawing.

The specimens decreased in volume uniformly as the temperature was lowered to approximately $+25^{\circ} \mathrm{F}$. Near this temperature, expansion, which was attributed to the beginning of freezing of water in the pores of the specimens, began and continued for about $30 \mathrm{~min}$ as the temperature of the bath was held at $25^{\circ} \mathrm{F}$. During this time the temperature at the centers of the specimens first increased to about $31^{\circ} \mathrm{F}$ and then returned to equilibrium with the bath. When both the volume and the temperature of the specimens became stable, point $C$ was observed. When cooling was resumed the 
specimens showed additional increases in volume and at $-25^{\circ} \mathrm{F}$ had not begun to contract. Such behavior indicated that not all of the freezable water in the specimen had been frozen at $-25^{\circ} \mathrm{F}$.

The specimens showed additional increases in volume during heating to a temperature of approximately $+16^{\circ} \mathrm{F}$, after which, with continued heating, they decreased in volume until point $F$, at $31^{\circ} \mathrm{F}$, was reached. Further heating produced increases in volume to point $G$.
The volume-temperature relationships in figure 16 are remarkable in indicating maximum transient increases in volume at $-25^{\circ} \mathrm{F}$ of approximately 0.80 percent for the plain, and 0.75 percent for the aerated specimen. Residual expansions were considerably smaller; 0.40 percent for the plain, and 0.30 percent for the aerated specimen. Residual linear expansions, determined by means of a length comparator, were 0.12 percent for the plain and 0.11 percent for the aerated specimen, and

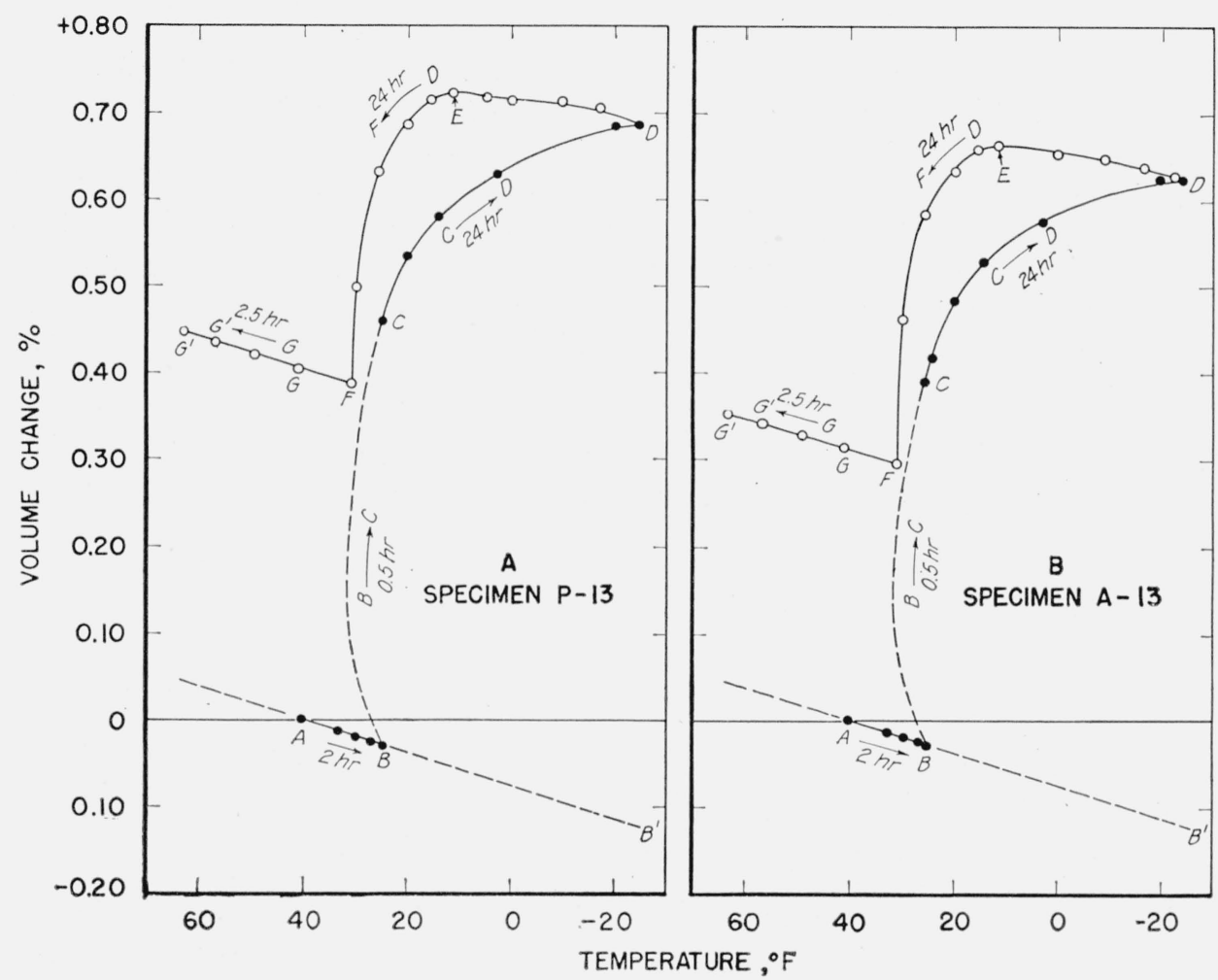

FIGURE 16. Volume-temperature relationships as obtained for specimens P-13 (plain) and A-13 (aerated), both vacuum saturated, subjected to a single slow cycle of freezing and thawing.

These specimens were 650 days old at the time of testing and had been tested in the air-dry condition at age 155 days (fig. 5). These specimens were in the dilatometers for 35 days following the air-dry storage and were then returned to air-dry storage for an additional 70 days before being vacuumsaturated. They were then kept immersed in water at $70^{\circ} \mathrm{F}$ for 1 year before testing in the vacuum saturated condition. Specimen $\mathrm{P}-13$ showed a decrease in Young's modulus (dynamic, flexural) of 65 percent 1 week after the completion of the cycle, and specimen A-13 showed a decrease of 60 percent e, Cooling; $\bigcirc$, heating.

After completion of the tests it was found that mercury had penetrated the specimens to a limited extent, through several small spalls or "popouts." A portion of the heating curves $F G$ has therefore been corrected in each case by an amount equal to the volume of mercury which had entered the specimens. agreed quite well with values obtained by dividing the indicated residual volume expansions by three. Several other specimens tested in the vacuumsaturated condition gave results of similar magnitude.

Other than the few spalls or popouts, there were no visible signs of disintegration in the specimens. 
Determinations of Young's modulus of elasticity, before and after testing, however, showed the following changes:

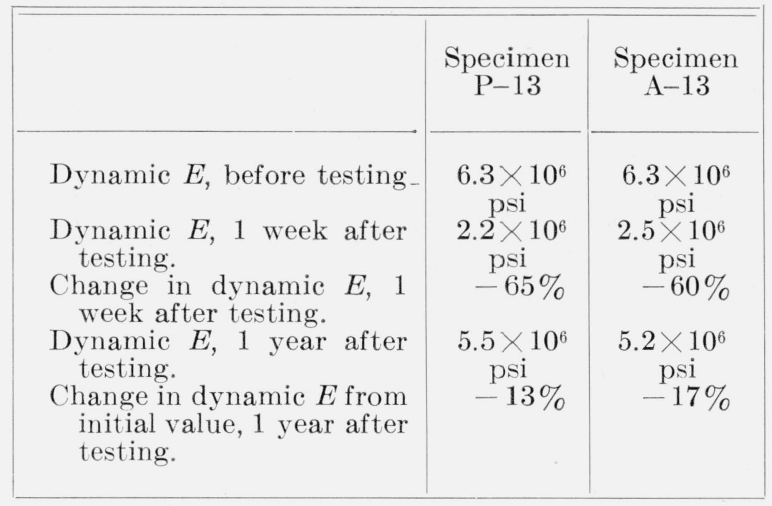

Had the dynamic $E$ determinations been made immediately following the completion of the freezing and thawing cycle, the decrease may have exceeded 90 percent, on the basis of previous experience in the "recovery" in dynamic $E$ in specimens subjected to freezing and thawing treatments [15]. Thus the vacuum saturated specimens were, for practical purposes, destroyed by a single cycle of freezing and thawing. In this connection it may be pointed out that the moisture condition is one not normally attained in laboratory specimens or in masses of concrete exposed to natural freezing and thawing. However, a fairly complete saturation may occur in top layers of horizontally exposed concrete surfaces. Under these conditions volume changes, as shown in figure 16 , would occur in the surface layers and thus account for the familiar type of deterioration known as scaling.

\section{Summary}

A detailed description has been presented of a mercury-displacement dilatometer for observing volume changes in moist, porous building materials during freezing and thawing.

Results presented have been confined to representative volume-temperature relationships for small cylindrical specimens cast from a concrete of one-mix design (plain and modified by the addition of an air-entraining agent) and made with one brand of normal portland cement and Potomac River aggregate.

The moisture condition of the specimens ranged from air-dry to vacuum-saturated. Most tests were performed upon specimens in a state of partial saturation, attained during various curing periods. These specimens, when tested, contained from 65 to more than 85 percent of the total water that they were made to contain upon being ovendried, evacuated, and resaturated following the freezing and thawing tests.

The types of freezing and thawing cycles employed varied in rates of cooling and heating within the $+40^{\circ}$ to $-20^{\circ} \mathrm{F}$ range. These cycles included a slow cycle, which required $32 \mathrm{hr}$, and a fast cycle, which required $1 \mathrm{hr}$ for completion.

The volume changes for all specimens tested in the air-dry condition were directly proportional to changes in temperature and independent of the rate of temperature change. The slopes of the volume-temperature relationships obtained were measures of the thermal coefficients of expansion.

The volume changes for the partially saturated specimens were generally not independent of the rate of temperature change, and showed departures from a uniform volume-temperature relationship such as that described for the air-dry specimens. These departures were believed to be effects of the conversion of water to ice (or ice to water) within the pore structures of the specimens.

The immediate effect of the freezing of water was a distension, which appeared to be directly related to the rate of cooling in those cases in which supercooling was minimized or absent.

Secondary effects of freezing were shrinkage and relaxation phenomena, which consisted of contractions in addition to the normal thermal contraction of the solid volume of a specimen.

The specimens usually showed a permanent "set" or residual expansion at the completion of a cycle. The residual expansions for repeated cycles were cumulative.

During slow cooling the pore water in a virgin specimen was apparently supercooled before it froze. The amount of supercooling diminished in succeeding repetitions of the slow cycle, except that when the specimen was maintained unfrozen for a sufficient time after any cycle, supercooling in the following slow cycle was again pronounced. There was no evidence of supercooling during the fast cycle.

Vacuum-saturated specimens subjected to one slow cycle showed distensions upon freezing, and residual expansions at the end of the cycle, more 
than 30 times as great as the corresponding volume changes in partially saturated specimens similarly tested. According to accepted criteria for soundness, these specimens definitely would have failed during one cycle of freezing and thawing.

Appreciation is expressed to P. H. Bates, former chief of the Clay and Silicate Products Division, at whose suggestion the study was initiated; to J. Tucker, Jr., who designed the concrete mixes; and to F. B. Hornibrook, P. H. Petersen, R. L. Blaine, N. Ernest Dorsey, and the late Phillip Turner, all of whose interest in the study was especially helpful.

Appreciation is also due Gerald Pickett of Kansas State College, Manhattan, Kans., and T. C. Powers of the Portland Cement Association, Chicago, Ill., for helpful discussion and comments during the progress of the study.

\section{References}

[1] A. B. C. Anderson and N. E. Edlefson, Soil Sci. 54, 221 to 232 (1942).
[2] G. J. Bouyoucos, J. Agr. Research 8, 195 to 197 (1917)

[3] W. N. Thomas, Dept. Sci. Ind. Research (Great Britain) Building Research Technical Paper No. 17 (1938).

[4] T. C. Powers and T. L. Brownyard, J. Am. Concrete Inst. 18, 933 to 969 (1947).

[5] H. Kreuger, Transactions of the Royal Swedish Institute for Scientific-Industrial Research, No. 24, Stockholm (1923).

[6] John Tucker, Jr., G. W. Walker, and J. Arthur Swenson, BS J. Research 7, 1067 (1931) RP389.

[7] L. B. Tuckerman, Proc. Am. Soc. Testing Materials 23, part 2, 602 (1923).

[8] Culbertson W. Ross, J. Research NBS 27, 197 (1941) RP1414.

[9] International Critical Tables II, 457-8 (1927).

[10] Federal Specification SS-C-191b for Cements; Portland (April 29. 1941).

[11] Federal Specification SS-C-158b for Cements, Hydraulic; General Specifications (Methods for Sampling, Inspection, and Testing) (May 20, 1946).

[12] S. L. Meyers, Ind. Eng. Chem. 32, 1107 (1940).

[13] Henry L. Kennedy, Proc. Am. Soc. Testing Materials 44, 821, (1944).

[14] T. C. Powers, J. Am. Concrete Inst. 16, 245 to 272 (1945)

[15] M. O. Withey, Proc. Highway Research Board 24. 174 to 202 (1944).

Washington, February 1, 1949. 